\title{
Evolution of Toll, Spatzle and MyD88 in insects: the problem of the Diptera bias
}

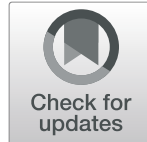

Letícia Ferreira Lima', André Quintanilha Torres ${ }^{1}$, Rodrigo Jardim', Rafael Dias Mesquita ${ }^{2,3}$ and Renata Schama ${ }^{1,3^{*}}$

\begin{abstract}
Background: Arthropoda, the most numerous and diverse metazoan phylum, has species in many habitats where they encounter various microorganisms and, as a result, mechanisms for pathogen recognition and elimination have evolved. The Toll pathway, involved in the innate immune system, was first described as part of the developmental pathway for dorsal-ventral differentiation in Drosophila. Its later discovery in vertebrates suggested that this system was extremely conserved. However, there is variation in presence/absence, copy number and sequence divergence in various genes along the pathway. As most studies have only focused on Diptera, for a comprehensive and accurate homology-based approach it is important to understand gene function in a number of different species and, in a group as diverse as insects, the use of species belonging to different taxonomic groups is essential.

Results: We evaluated the diversity of Toll pathway gene families in 39 Arthropod genomes, encompassing 13 different Insect Orders. Through computational methods, we shed some light into the evolution and functional annotation of protein families involved in the Toll pathway innate immune response. Our data indicates that: 1) intracellular proteins of the Toll pathway show mostly species-specific expansions; 2) the different Toll subfamilies seem to have distinct evolutionary backgrounds; 3) patterns of gene expansion observed in the Toll phylogenetic tree indicate that homology based methods of functional inference might not be accurate for some subfamilies; 4) Spatzle subfamilies are highly divergent and also pose a problem for homology based inference; 5) Spatzle subfamilies should not be analyzed together in the same phylogenetic framework; 6) network analyses seem to be a good first step in inferring functional groups in these cases. We specifically show that understanding Drosophila's Toll functions might not indicate the same function in other species.

Conclusions: Our results show the importance of using species representing the different orders to better understand insect gene content, origin and evolution. More specifically, in intracellular Toll pathway gene families the presence of orthologues has important implications for homology based functional inference. Also, the different evolutionary backgrounds of Toll gene subfamilies should be taken into consideration when functional studies are performed, especially for TOLL9, TOLL, TOLL2_7, and the new TOLL10 clade. The presence of Diptera specific clades or the ones lacking Diptera species show the importance of overcoming the Diptera bias when performing functional characterization of Toll pathways.
\end{abstract}

Keywords: Arthropoda, Evolution, Gene family, Innate immunity, Hexapoda, Pelle, Pellino, Tube, Toll pathway, SSN

\footnotetext{
*Correspondence: renata.schama@gmail.com; schama@ioc.fiocruz.br

'Laboratório de Biologia Computacional e Sistemas, Oswaldo Cruz

Foundation, Fiocruz, Rio de Janeiro, Brazil

${ }^{3}$ Instituto Nacional de Ciência e Tecnologia em Entomologia

Molecular-INCT-EM, Rio de Janeiro, Brazil

Full list of author information is available at the end of the article
}

(c) The Author(s). 2021 Open Access This article is licensed under a Creative Commons Attribution 4.0 International License, which permits use, sharing, adaptation, distribution and reproduction in any medium or format, as long as you give appropriate credit to the original author(s) and the source, provide a link to the Creative Commons licence, and indicate if changes were made. The images or other third party material in this article are included in the article's Creative Commons licence, unless indicated otherwise in a credit line to the material. If material is not included in the article's Creative Commons licence and your intended use is not permitted by statutory regulation or exceeds the permitted use, you will need to obtain permission directly from the copyright holder. To view a copy of this licence, visit http://creativecommons.org/licenses/by/4.0/. The Creative Commons Public Domain Dedication waiver (http://creativecommons.org/publicdomain/zero/1.0/) applies to the data made available in this article, unless otherwise stated in a credit line to the data. 


\section{Background}

Arthropoda is the most numerous and diverse metazoan phylum [1-4]. It is an extremely successful group, with species present in almost all habitats on earth. Insects alone account for more than 1 million species that have a wide spectrum of adaptations [1]. Given their abundance, evolutionary resilience and widespread presence, many insect species importantly impact human health [5]. Many are vectors of pathogens and others are pests of agricultural or metropolitan importance [5-7]. Pollinators and other species responsible for recycling dead matter are also of significant importance in a One Health perspective $[8,9]$. Insect presence in most habitats, with their wide variety of dietary habits and behavior, also means that they encounter various microorganisms such as bacteria, fungi and viruses, many of which may be pathogenic. As a result, insects have evolved mechanisms for pathogen recognition and elimination [10-12]. Although it is not clear if insects have some type of adaptive immune response [1316], cellular and humoral responses against pathogens have been well characterized [10, 17-19].

Innate immunity is the first line of defense that controls the initial steps of the immune response in multicellular organisms [11, 20-24]. In insects, four different immune signaling pathways have been described: Imd, Toll, JAK/STAT and RNAi [21, 25]. The RNAi pathway mainly controls virus replication [26] while the JAK/ STAT pathway regulates immune response genes related to viral and bacterial infections. The Imd and Toll pathways are inflammatory responses that include the recognition of pathogens and expression of a wide spectrum of anti-microbial peptides (AMPs) through the activation of NF-kB-like (Nuclear Factor-kappa B-like) transcription factors [27-30]. Both signal transduction pathways link the recognition of pathogen-associated molecular patterns (PAMPs) by Pathogen Recognition Receptors (PRRs) with transcriptional activation [31-35]. The Toll pathway has first been described as part of the developmental pathway for dorsal-ventral differentiation in Drosophila [36, 37]. Since then, the many gene families involved in the different Toll pathways have been shown to be important not only for immune response but for all kinds of inflammatory and non-inflammatory responses even without pathogen presence [29, 38]. Although previously this pathway has only been linked to defense against gram-positive bacteria and fungi, more recently, in Drosophila, many different functions and pathways have been discovered where Toll genes are essential.

In the fruit fly, it has been demonstrated that Toll signal transduction initiates when a cleaved protein dimer ligand binds to the extracellular domain of Toll receptors [39-42]. Conventionally, a phosphorylation cascade then initiates with the intracellular domain of Toll binding to another transmembrane protein, MyD88 [4346]. Subsequently, MyD88 forms an heterotrimer with the scaffolding protein Tube and Pelle (a protein kinase) through their death domains (DD), initiating the signal transduction pathway $[47,48]$. With Pellino's positive regulation of Pelle [49], this complex phosphorylates Cactus which releases Dorsal or Dif (Dorsal-related immunity factor), both members of the Rel family of transcription factors, which translocate into the nucleus activating different genes, including antimicrobial ones such as the antifungal peptide Drosomycin, for example [10, 48, 50, 51].

Toll-like receptors (TLRs) are a family of type I transmembrane proteins with an ectodomain composed of repeats of leucine-rich regions (LRRs) flanked by cysteinerich modules and an intracytoplasmic signaling TIR domain (a Toll/interleukin-1 receptor domain homologue) [51-56]. To date, nine genes have been found in Drosophila melanogaster's genome and similar numbers were found in other insects [51, 57-60]. Although in humans Toll-like receptors act in pathogen recognition, in insects, Toll functions more like cytokine receptors, mostly for the endogenous protein Spatzle (Spz) [54, 61-64]. Spatzle was also originally identified as a component of the dorsalventral patterning signaling pathway that acts upstream of Toll. Since then, other five Spatzle homologues (Spz2-6) have been identified in Drosophila [55]. All of them encode extracellular proteins with neurotrophin-like cysteine-knot domains. Spatzle is activated by protease cleavage [65] and its C-terminal fragment is believed to be the one to bind to the extracellular domain of Toll and activate its pathway $[63,66]$. Upon cleavage, the Spatzle fragments form a dimer held together by intermolecular disulphide bridges [42]. In the embryo, precise spatial regulation of Spatzle activation is necessary for normal dorsal-ventral development but in larval and adult stages both Spatzle and its upstream activating proteases are openly circulating in the hemolymph $[67,68]$. The precise mechanisms by which Spatzle is recognized and activated and how this leads to which Toll pathway is activated is not completely clear. In Drosophila, danger signals and Damage Associated Molecular Patterns (DAMPs) may also activate Persephone, one of the proteases responsible for cleaving Spatzle [38, 69, 70]. This response seems important in differentiating harmful microbes from commensal ones.

The finding of Toll-like structures in vertebrates led to the belief that the innate immune system was extremely conserved. Nevertheless, although very similar in structure and pathway formation, vertebrate and most Arthropod Toll genes seem to be associated with two unrelated events of gene expansion [23, 51]. In arthropods, genes from both Toll and Imd signaling pathways are conserved, with more sequence variation in recognition and effector 
genes than in those in the middle of the pathway [60, 71, 72]. Nevertheless, there is also variation in presence/absence, copy number and sequence divergence in various genes along the pathway. As more taxonomic groups are investigated, more diversity is found, sometimes with whole pathways missing. In aphids and chelicerates, for example, some or all Imd genes are missing [71, 73].

The fact that most studies have focused on Diptera obscured the knowledge of the significance of these immune system related genes in other insect groups. For a comprehensive and accurate homology-based approach it is important to understand gene function in a number of different species and, in a group as diverse as insects, the use of species belonging to different taxonomic groups is essential. Given the large evolutionary time scales, many lineage specific changes may have occurred. Insects first appeared in the fossil record $\sim 412$ million years ago (MYA) and it is difficult to predict function from BLAST searches when comparing species that have diverged hundreds of millions of years ago. The Dipterans, for example, seem to have emerged in the Permian ( 250 MYA) and the Culicidae genera Anopheles and Aedes seem to have diverged $~ 170$ MYA [1, 74-76]. Also, it has already been demonstrated that in many cases the presence of copy number variation can be accompanied by changes in function [71, 77]. Newly sequenced insect genomes have their genes annotated based on sequence homology to known genes from other species, so it is crucial that homology-based studies are performed so we better understand the different gene duplications in these protein families.

In this study, we analyze 39 insect genomes belonging to 13 insect orders encompassing the three principal Neoptera groups (Polyneoptera, Paraneoptera and Holometabola) and the Palaeoptera (Odonata and Ephemeroptera) $[1,78]$ together with the Crustacea Daphnia pulex to shed some light in the evolution of six gene families of the Toll pathway in Insecta. We focused on genes previously considered to be less diverse and, therefore, less investigated. To our knowledge, this is the first genomic study with so many insect orders to focus specifically on Toll receptors and other gene families involved in the Toll pathway, which encode proteins that interact either directly or indirectly with Toll.

\section{Results}

\section{Protein searches}

Sequences of putative Toll (396), MyD88 (60), Spatzle (1069, of which 476 are unique ones), Tube (55), Pelle (47) and Pellino (75) proteins were identified from the predicted protein sets of 39 insects and from the crustacean $D$. pulex. Table 1 summarizes the organisms analyzed and number of copies of each gene found in each genome and their source. Only in a few cases the automated genome predictions did not contain one or more of the proteins expected for the protein families and subfamilies analyzed and these were, therefore, searched for with Exonerate searches of the scaffolds (see Additional file 1). Incomplete predictions were recovered and the protein was only counted as existent in a species when a significant identity value and good coverage was found with subsequent BLASTp searches. A supplementary text file, in FASTA format, with Transeq translation of proteins recovered with Exonerate is available (see Additional file 2).

Among the Toll subfamilies, Toll9 genes were not found in the six Hymenoptera species analyzed and the only Trichoptera genome searched, suggesting that this subfamily was lost in these lineages. Nevertheless, since we only have one Trichoptera species in our study, problems in the genome assembly should not be ruled out either. Small or partially predicted proteins for the species Lutzomyia longipalpis, Phlebotomus papatasi, Glossina brevipalpis and Acyrthosiphon pisum, possibly belonging to the Toll9 subfamily, were found with Exonerate. Although they were counted as Toll9 they were not used in the phylogenetic analysis due to their incomplete prediction (see Additional file 1). For the Toll8 subfamily, one possible gene for the species Stomoxys calcitrans was found but reliable predictions could not be made for the species Ctenocephalides felis. For Toll6, one possible gene was found for the species C. felis, Locusta migratoria, Rhodnius prolixus, Bactrocera dorsalis and two partial predictions were found for Heliconius melpomene. No genes were found for $D$. pulex in this subfamily. For the Toll2_7 subfamily, new partially predicted genes were found for D. pulex, Ladona fulva and L. migratoria (see Additional file 1). For the new Toll10 subfamily, no genes were found for the species D. pulex and L. fulva, but partials were found for Megachile rotundata, Nasonia vitripennis, L. migratoria and C. felis. No gene for this subfamily was found in L. fulva and D. pulex. In Diptera, Toll10 genes were only found in the Culicidae while none were present in the Neodiptera (Schizophora) and Psychodidae species, suggesting it was lost in these two lineages.

Although searched for, the protein Pelle was also not found in the protein sets or with Exonerate searches of the genomes of the species Rhagoletis zephyria, Phlebotomus papatasi, Megachile rotunda, Bombus impatiens, Acromyrmex echinatior, Manduca sexta and Limnephilus lunatus. Since what differentiates Pelle from other ATP binding proteins is the presence of its Death Domain (DD) and lack of other protein kinase domains, we only included genes that had at least a partial DD together with a protein kinase (Pkinase) domain and no other. In this case, it might be possible that poorly predicted genome regions might have been the cause of 


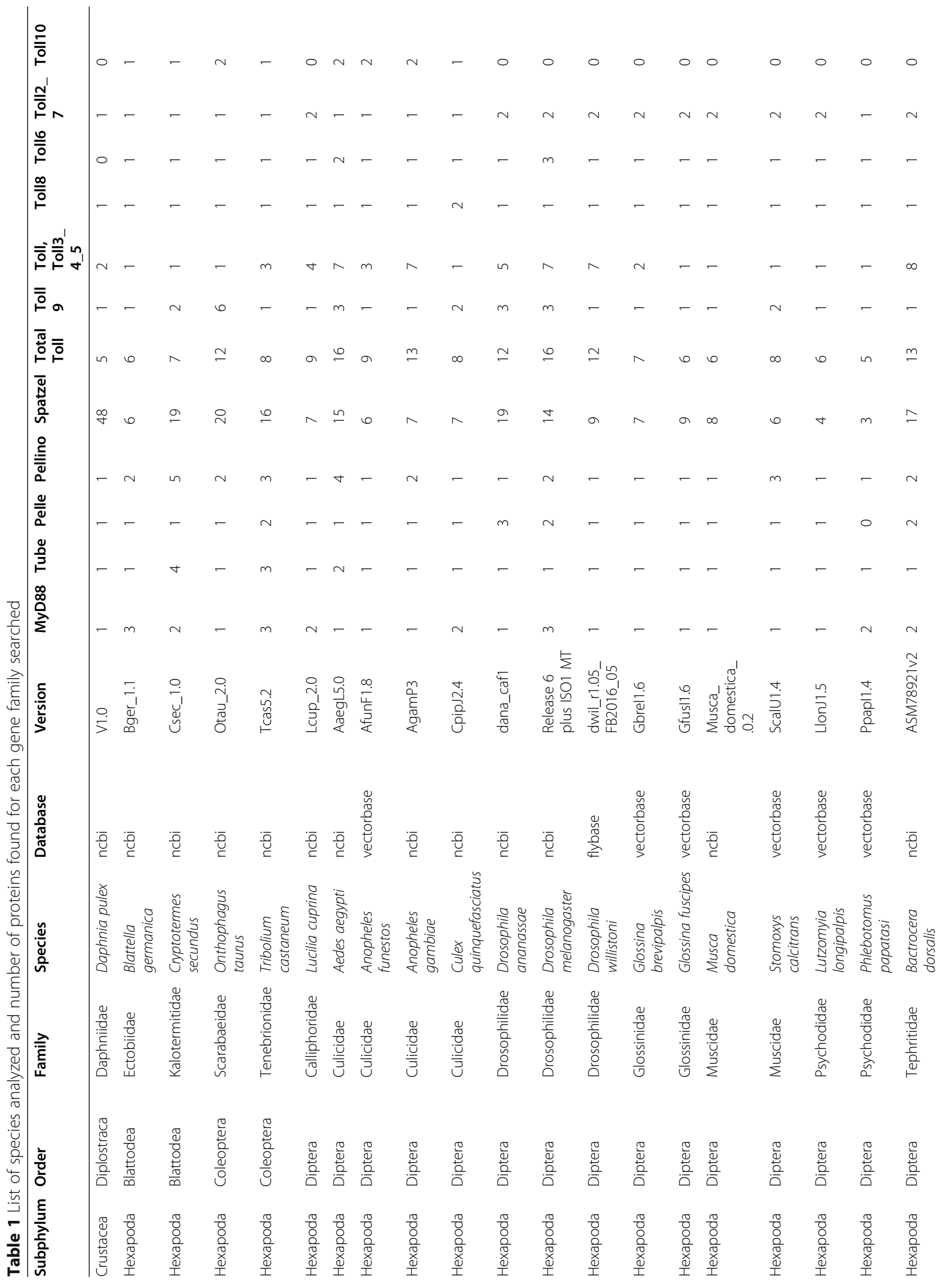




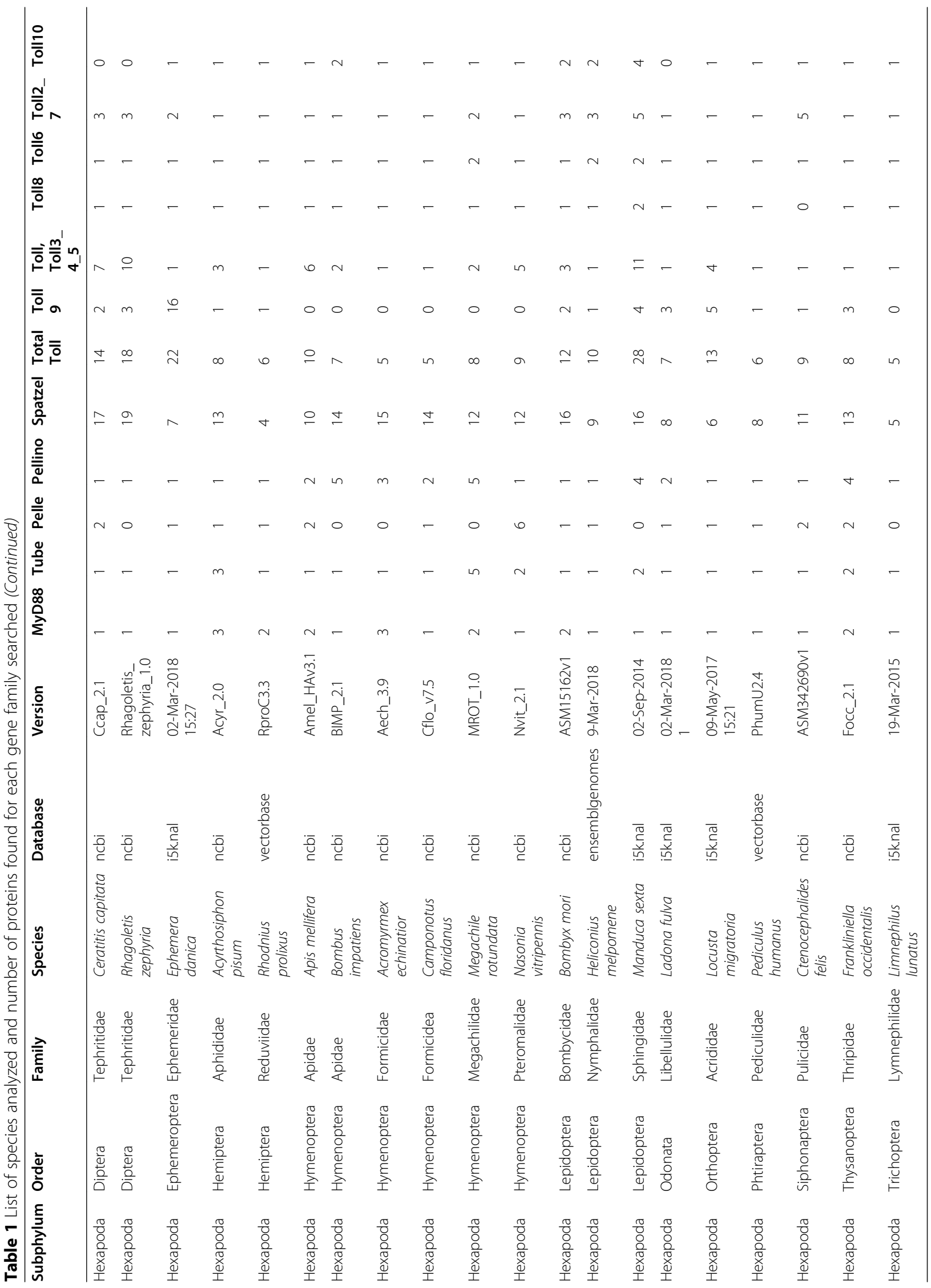


gene absence in these species, especially because, apart from Trichoptera, in all other cases other species of the same order did have the gene (Table 1). For MyD88, in addition to the 10 genes recovered with Exonerate (see Additional file 1), we were able to retrieve complete protein sequences for the species Cryptotermes secundus (XP_023725093.1, XP_023725092_1), Stomoxys calcitrans (XP_013115653_1) and Bombyx mori (XP_ 004921573_1) with BLASTp searches in the GenBank database, even though these were not present in their genome's protein sets and not found with Exonerate searches. Two new Tube genes were found for the species Blattella germanica and Limnephilus lunatus and only one Pellino gene for Limnephilus lunatus was found. Twenty-one new putative Spatzle proteins were found with Exonerate searches (see Additional file 1).

A few proteins found on the HMMsearches and most of the new genes found with Exonerate were not completely predicted and, therefore, were not used in a phylogenetic context. Nevertheless, they were used in the Sequence Similarity Network analyses and counted as present in the genomes in Table 1. With this approach it was possible to count all genes with the expected domains within the genomes analyzed but still have reliable phylogenetic inferences.

\section{Sequence similarity networks}

Unlike phylogenies, SSNs do not infer evolutionary relationships but demonstrate groups of similar sequences which, together with other sequence information, might suggest similar function or another trend [79-81]. We used SSNs to better understand the different functional groups present in the proteins that have the TIR and Spatzle domains. For the TIR domain, the network contains all sequences retrieved with the HMMsearches and includes edges with an alignment score cut off of 20 . This separates the proteins identified as Toll from MyD88, which form separate clusters (see Additional file 3). Toll proteins form two clusters with the smaller one containing Toll sequences that are similar to interleukin-1 receptors and sequences with partial TIR domain and that, therefore, were not used in the phylogenetic analysis (TOLL 2, (see Additional file 3)). Two nodes in grey are outliers and have not formed edges with any other node even though a low stringency SSN was created. These sequences (GBRI043149-PA and XP_ 026472669.1) were similar to SAP30 and zinc finger genes on BLASTp searches and were retrieved by FAT but do not have a complete TIR-like domain. Sequence identity varied from 25 to $100 \%$ and the median for all Toll genes was $34.48 \%$ and MyD88 36.88\%. A higher stringency network was created to better understand the functional groups within Toll proteins (see Additional file 4). In this case, an alignment score of 20 was used to create the network and, in Cytoscape, an identity value of $50 \%$ was also used as threshold and edges with lower values were deleted from the network. The nodes were colored based on taxonomic groups. This analysis already shows groups of taxa-specific clusters, suggesting lineage specific expansions (this is better visualized in the phylogenetic analysis below).

For the SSN of proteins with Spatzle domain (Fig. 1) (see also Additional file 5) an alignment score of 30 was used which formed clusters of sequences with $25-100 \%$ sequence identity. The number of different clusters that have no edges with others already suggests low sequence identity among functional groups. The species Phlebotomus papatasi and Anopheles funestos have the lowest protein number [3] and the highest number is found in D. pulex [35]. Seven bigger (more than seven nodes) different functional groups were formed that more or less coincide with the different D. melanogaster's Spatzle proteins identified previously [55] (triangle shaped nodes in Fig. 1 and Additional file 5). One group (light green in Fig. 1) is formed by sequences of uncharacterized proteins of $D$. pulex only. Other $D$. pulex proteins can be found in five isolated nodes, and one node each can also be found in the Spz2, Spz5, Spz6 and Spz7 clusters described below (see Additional file 5). The D. pulex cluster has one edge with the Spz2 protein cluster (light pink, Fig. 1). This cluster is composed of proteins from species of almost all insect orders analyzed with Coleoptera, Trichoptera, Ephemeroptera and Orthoptera being the only ones absent. Another cluster contains both Spz3 (yellow) and Spz4 (blue) proteins and even with a higher identity value stringency it is not possible to further differentiate these two groups. The cluster contains proteins from all insect orders analyzed that fall on both Spz3 and Spz4 regions, however, only one node of Orthoptera proteins is formed. Another cluster is formed by Spz5 sequences (orange) with all insect orders, with the exception of Orthoptera. The cluster of Spz6 proteins (red) contains sequences from all insect orders except Orthoptera and Trichoptera. One smaller cluster, containing non-Diptera uncharacterized proteins (black cluster) from all insect orders except Diptera and Orthoptera was named Spz7. Other smaller clusters, formed mostly by species-specific non-identified sequences and some isolated sequences, are colored grey.

A larger more diverse cluster of Spatzle proteins (cyan) was formed. If we look closely at the clusters within it, we can see five taxa-specific node clusters (Fig. 1 and Additional file 5). One is formed by Drosophila species, another by other Schizophora species, a third one contains all Culicidae, the fourth with $A$. pisum sequences and the fifth with Hymenoptera species sequences (see Additional file 5). In the middle, nodes with Siphonaptera, Coleoptera, Blattodea, Orthoptera, Trichoptera, 


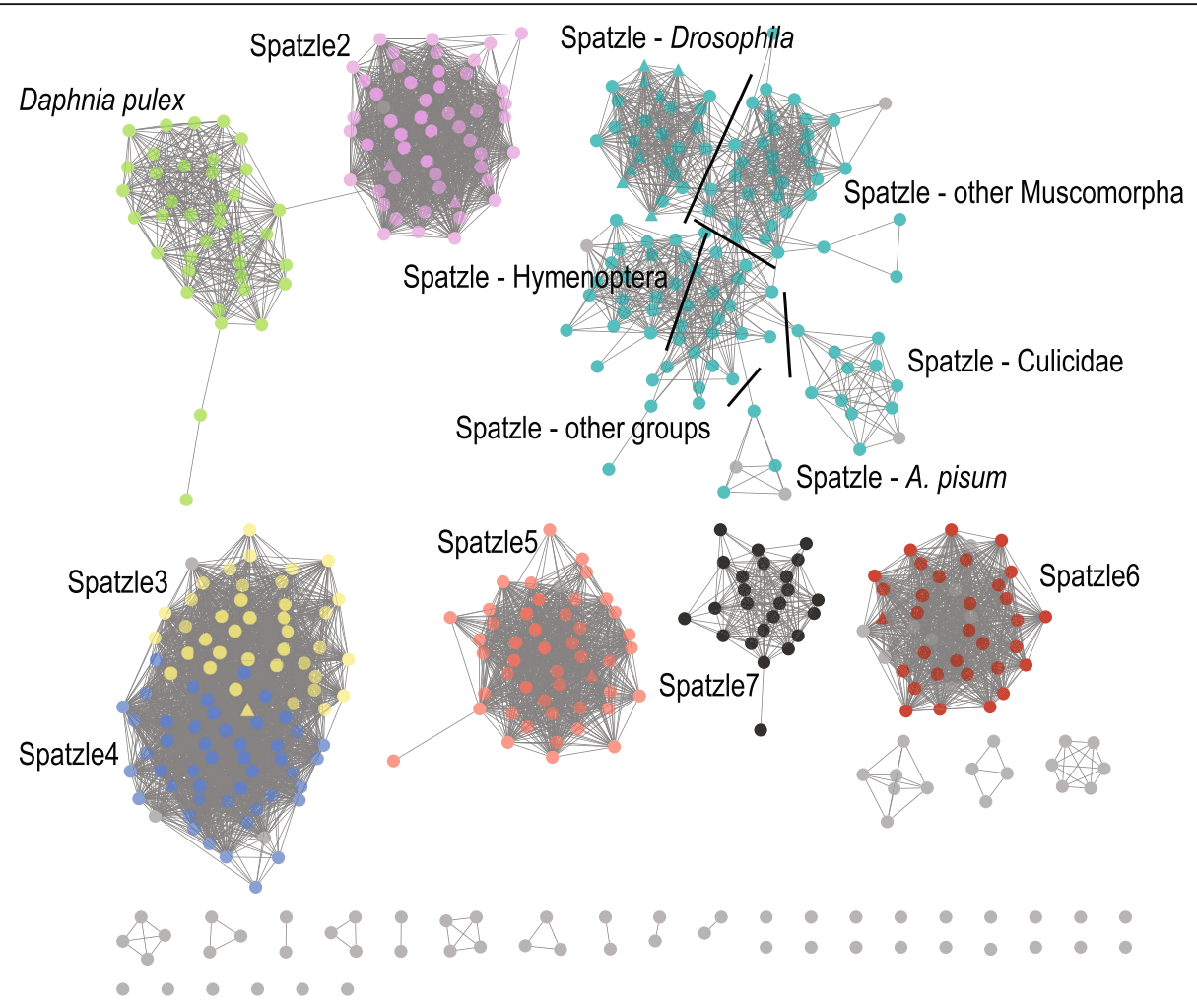

Fig. 1 SSN of the Spatzle domain proteins found on FAT searches. Each node represents proteins sharing 100\% sequence similarity and edges with an alignment score cut-off of 30 between proteins. Clusters are colored based on OrthoMCL, Blast results and the presence of Drosophila melanogaster's Spatzle genes (triangle shaped nodes). Group names were given based on D. melanogaster's gene name. Grey nodes are unidentified sequences

Thysanoptera, Phtiraptera, Psychodidae and the Hemiptera $R$. prolixus sequences are present (see Additional file 5). In Fig. 1, sequences in grey within the different Spatzle clusters did contain a Spatzle domain that were either too small for a confirmation of their orthologous group in OrthoMCL or had other domains attached as well. Due to the high sequence divergence between and within functional groups a phylogenetic analysis was not performed. Phylogenetic analyses of protein sequences with less than $40 \%$ sequence identities are not reliable [82], especially when an ancient radiation has happened [83], as is the case for the gene family here. A conservative approach is important due to the possibility of multiple substitutions having occurred at the same site that would not be taken into account in the amino acid substitution model and due to the short internal branches.

\section{Phylogenetic analyses}

Our phylogenetic analyses of the protein alignment of the six gene families of the Toll pathway analyzed here showed very different characteristics (Figs. 2, 3, 4 and 5; (see Additional files 6, 7, 8 and 9)). In all cases, there are duplications within the genomes even though, for the intracellular protein families, the duplications were not as extensive as for Toll and Spatzle (Table 1). For Tube,
Pelle, Pellino and MyD88, most species have only one copy of each gene and, when there are duplications, they mostly happened within each taxonomic lineage (see Additional files 6, 7, 8 and 9). When we look at the phylogenetic analysis of Tube (see Additional file 6), we can see that, in Diptera, only $A$. aegypti has two copies of this gene with all other species having only one. The focus in Diptera might have been the reason why most studies cited this and other signal transduction protein families of the Toll pathway as being very conserved [60, 72]. Nevertheless, when we look further to the other insect orders analyzed, another seven had gene duplications (Table 1). At least one Tube gene was found in each genome, including the outgroup $D$. pulex (Table 1 and Additional file 6). The bootstrap values for most interior branches are not high, indicating that there is not enough information within the sequences to confidently infer the relationships among higher taxonomic groups. This might be the reason why the Schizophora Diptera cluster with Hymenoptera instead of with the Culicidae, as was expected [74]. Nevertheless, this is not surprising since the whole insect phylogeny was in debate a few years ago and, as a matter of fact, still is in some points, even though the amount of data used to estimate the relationship of its taxa has greatly increased [3, 74, 78, 85]. 
One point is certain, within the lineages that have duplications they were species-specific (with high bootstrap support) with gene expansions within each genome (see Additional file 6). To some degree, the same happens in Pelle, Pellino and MyD88, the other signal transduction gene families (Table 1 and Additional files 7, 8 and 9).

In the phylogenetic analysis of Pellino, of the 40 genomes analyzed 17 had gene duplications and at least one gene was found in each genome (Table 1 and Additional file 7). In this case, some of the more basal branches do have high bootstrap values (see Additional file 7) and, apart from two short sequences from $L$. fulva and one from $R$. zephyria, all sequences fall with high bootstrap values within their taxonomic clade. Except for L. fulva and F. occidentalis, all other duplications, when they occurred, have been within a species genome and bootstrap values are high in each duplication cluster (see Additional file 7). Interestingly, more gene expansions seem to have occurred in the Hymenoptera taxonomic group, with 5 of the 6 species analyzed having more than 2 copies of this gene (Table 1 and Additional file 7). However, this can be an artifact due to the high number of Hymenoptera species analyzed. Both species of Blattodea and Coleoptera analyzed, for example, also have at least two copies of this gene. This indicates that there were more gene expansions in these insect orders than in Diptera, a highly studied group.

In the phylogenetic analysis of Pelle, of the 40 genomes analyzed here nine had gene duplications but, in this case, no proteins were found in eight species even with Exonerate searches (Table 1 and Additional file 8). This is the only gene family analyzed where no genes were found within a species and this might have happened due to the high variability rates found within this protein [72] or, more likely, as discussed above, due to incomplete genome assemblies or gene predictions. This happened in the Hymenoptera, Psychodidae, Tephritidae and Lepidoptera. Again, when duplications did occur, they were clustered with high bootstrap values within a species-specific clade. In the case of MyD88 proteins, of the 40 genomes analyzed here 15 had gene duplications and at least one protein was found in each of the species analyzed, including the outgroup (Table 1 and Additional file 9). All duplications seem to be speciesspecific with high bootstrap support for these clades, nevertheless, a $B$. dorsalis sequence is found inside Schizophora but outside the Tephritidae clade. Although basal branches do not have high support, apart from Coleoptera and Tephritidae, most taxonomic specific clades do (see Additional file 9).

The phylogenetic analysis of the TIR domain of all Toll sequences retrieved from the species analyzed was able to divide the family into three well supported clades with different evolutionary paths (yellow, green and blue triangles; Fig. 2). All genomes had duplications of Toll genes, with the species Manduca sexta having the highest number [28] and a few other species being on the lowest range of five genes (Table 1). Numbers varied widely within taxonomic groups and gene subfamilies (Table 1). The first well supported clade $(100 \%$ bootstrap) encompasses what we named the TOLL9 subfamily due to the presence of $D$. melanogaster's Toll9 protein sequences (Yellow group in Fig. 2 and Fig. 3). The clade is further divided into other three well supported clades and, for this subfamily, we can see that in many genomes the gene duplications have occurred sometime in the ancestor lineage of different taxonomic groups. Differently from the other four gene families already analyzed here many were not only speciesspecific expansions. In $L$. fulva's genome, for example, there are three different genes, each one belonging to one of the three different TOLL9 clades (Fig. 3). The presence of all three Toll9 genes in an Odonata species suggests that all three genes might have been present in the ancestral Pterygota lineage and one or another have been lost in many taxonomic groups. There are also examples of more recent species-specific duplications with genes from the same genome grouping with high confidence in many cases (Fig. 3). The Coleoptera species $O$. taurus and the Ephemeroptera E. danica have the largest gene expansions. This gene is also present in the genome of the outgroup D. pulex.

The second highly supported Toll clade (99\% bootstrap; green triangle on Fig. 2), contains a few subclades without good bootstrap support in the interior branches (Fig. 4). It includes D. melanogaster's Toll, Toll3, Toll4, and Toll5 genes but, due to the lack of tree resolution, it is difficult to determine which of these, if any, might have been the ancestral gene in Arthropoda. It is clear that all genomes analyzed, even the outgroup $D$. pulex, have at least one copy of this Toll clade, but to which $D$. melanogaster gene other Arthropoda genes are closest it is not possible to say with confidence. Apart from Diptera, in all other species all duplications seem to be species-specific, clustering with high bootstrap values. Nevertheless, for Diptera species, many duplications seem to have happened in an ancestral lineage. The species $R$. zephyria, C. capitata and B. dorsalis, for example, have a few duplications that seem to have originated in the ancestral lineage of Tephritidae. The TOLL subfamily (where we find the original Toll gene described for $D$. melanogaster) seems to be specific to Schizophora; this Diptera-specific clade has high bootstrap support (95\%, black line rectangle in Fig. 4).

The third clade with high bootstrap (100\%; blue triangle in Fig. 2) is composed of four subclades with high bootstrap values (Fig. 5). The first subclade was named TOLL8 (83\% bootstrap; Fig. 5) due to the presence of $D$. 


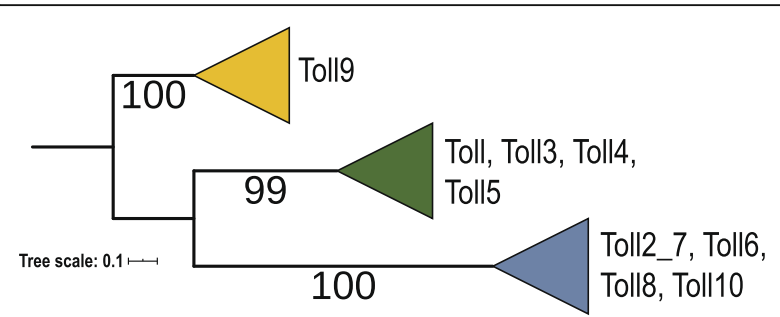

Fig. 2 Maximum likelihood phylogeny of the protein alignment of the TIR domain for TOLL sequences. The branches were collapsed for a better visualization of the three main Toll clades. In yellow the Toll9 subclades, in green the clade containing TOLL, TOLL3, TOLL4 and TOLL5 subclades and, in blue, the one containing TOLL2_7, TOLL6, TOLL8 and TOLL10 subclades. Numbers on branches are bootstrap support values from 1000 replicates and only numbers above $50 \%$ are shown. Scale bar is substitutions per site. The image was created using iTOL [84]

melanogaster's Toll8 (also called Tollo) gene. The genes in this clade seem very conserved and, apart from $M$. sexta (two identical copies), C. quinquefasciatus (two copies) and C. felis (not found), most species have only one copy of this gene. The outgroup $D$. pulex, has one TOLL8 subfamily sequence, indicating that this gene was present in the Pancrustacea ancestral lineage. The second subclade was named TOLL6 (98\% bootstrap; Fig. 5 ) due to the presence of $D$. melanogaster's Toll6 gene. This also seems a very conservative Toll subfamily with most species having only one gene and duplications occurring in only four of the genomes (A. aegypti, M. rotunda, M. sexta and D. melanogaster; Fig. 5). Again, most genomes seem to have at least one copy of this gene, although it was not found in the outgroup D. pulex.

A third subclade was named TOLL2_7 (100\% bootstrap in Fig. 5) due to the presence of D. melanogaster's Toll2 (also known as 18wheeler) and Toll7 genes. These genes are only present in Schizophora species and its duplication might have happened in the ancestral lineage of Diptera and, afterwards, one copy was lost in the Psychodidae and Culicidae (100\% bootstrap support; Fig. 5). Perhaps, more likely, it could be a duplication that happened in the ancestral Schizophora lineage since low bootstraps (70 and $72 \%$ ) are found in the interior branches. Since these genes are an innovation in Diptera, it is difficult to say to which, if any, the insect ancestral sequence was more similar to, so we decided to name this subfamily TOLL2_7. The phylogenetic tree clearly suggests that duplications have also occurred in the ancestral lineage of the Lepidoptera (100\% bootstrap support; Fig. 5), with three distinct clusters of $H$. melpomene, M. sexta and B. mori sequences. The outgroup D. pulex is not present in this clade. The fourth subclade has a high support without the $E$. danica sequence (100\% bootstrap; Fig. 5) but a lower one if we include this species (67\% bootstrap support). It is an interesting clade with only Culicidae species representing the order Diptera. Since no known D. melanogaster gene is present, we decided to name it TOLL10, following $D$. melanogaster's nomenclature. In this clade there were gene duplications in the genomes of $O$. taurus and $B$. impatiens and lineage specific duplications in the Culicidae and Lepidoptera. One $R$. zephyria sequence does not group with high support anywhere in the Blue clade. This might be because its sequence is highly divergent or because it's genome assembly and gene prediction are not good. Problems with genome assembly and gene prediction can be an issue [86], especially when a large number of highly divergent species are comparatively analyzed.

\section{Discussion}

In this work we evaluated the diversity of Toll pathway gene families in 39 Arthropod genomes, encompassing 13 different Insect Orders, using D. pulex as an outgroup. Combining the phylogenetic, domain and residue analysis our data indicates that: 1) As suggested before, intracellular proteins of the Toll pathway have fewer gene duplication events, and we found here that when they happened, they usually are species-specific with important implications for the functional characterization of these genes; 2) we also found that not all Tolls are created equal, and the different Toll subfamilies seem to have different evolutionary backgrounds; 3 ) the different patterns of gene expansion observed in the Toll phylogenetic tree indicate that homology based methods of functional inference might not be accurate for some subfamilies (such as TOLL, TOLL2_7 and TOLL10); 4) the Spatzle subfamilies are highly divergent and should not be analyzed together in the same phylogenetic framework as has been done previously; 5) network analyses seem to be a good first step in inferring functional groups in these cases. We were also able to see that Toll9 was lost in the ancestral lineage leading to Hymenoptera, and, as suggested before, Toll9 forms a separate subgroup within the Toll family. Moreover, we show that the other Toll subfamilies can also be clustered into other two highly supported clades, where Toll, Toll3, Toll4, Toll5 form a subfamily with more lineage specific expansions in Diptera, whereas the third subclade formed of Toll8, Toll6, Toll2_7 and Toll10 gene subfamilies, seems more conserved. Toll seems to be specific to Schizophora and Toll3, Toll4 and Toll5 are all clustered in Diptera clades making it difficult to estimate which, if any, is the ancestral gene in insects. The presence of a D. pulex sequence indicates that Toll8 might have been present in the Pancrustacea, but Toll6, Toll2_7 and Toll10 seem to be Pterygota specific. To our knowledge this is the first work to show, in a phylogenetic framework, that the evolutionary backgrounds of the different Toll pathway genes of the signaling cascade are very 


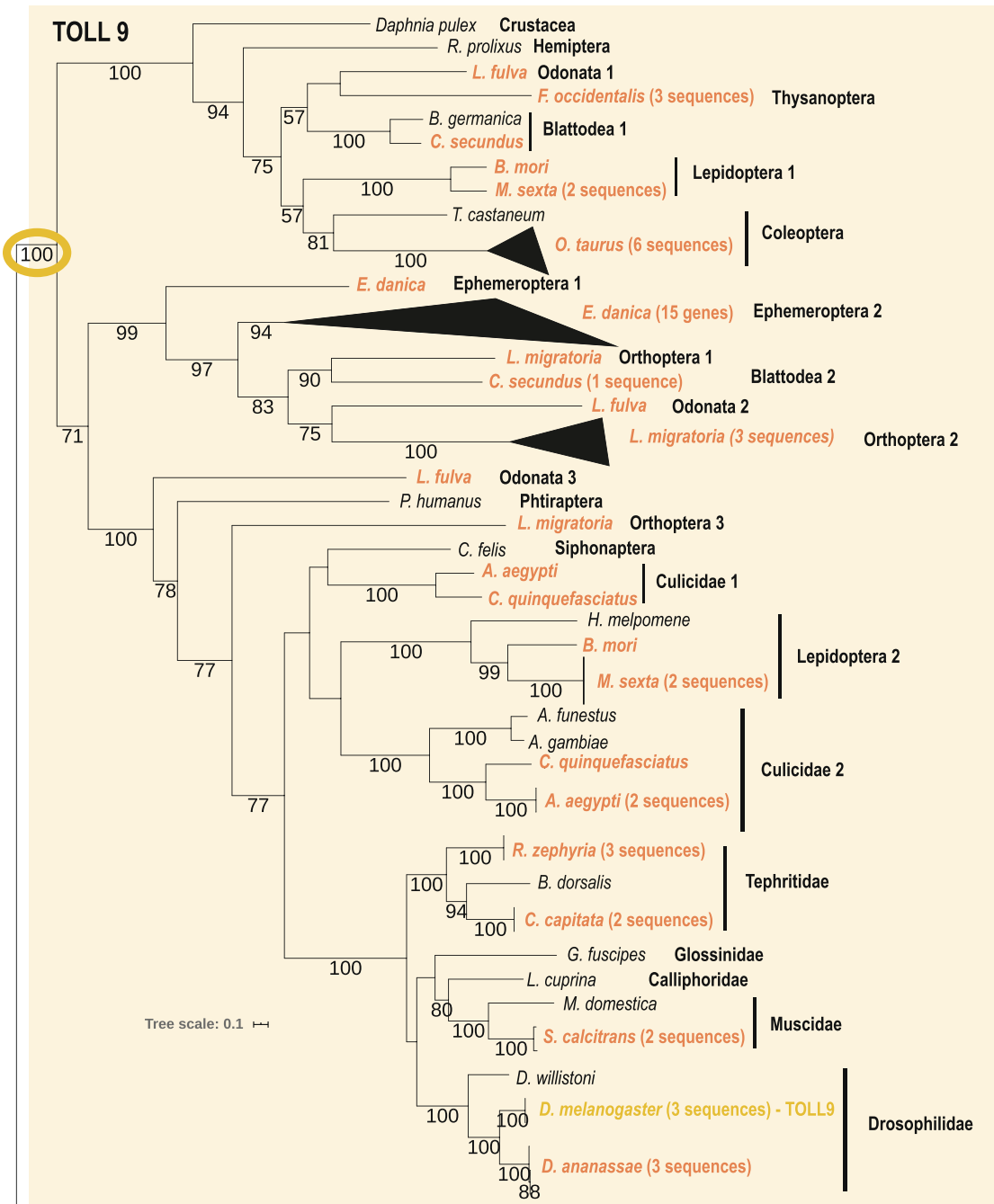

Fig. 3 Maximum likelihood phylogeny of the yellow clade of TOLL9 proteins. Species with gene duplications are highlighted in orange and Drosophila melanogaster's Toll9 genes are highlighted on the tree. Numbers on branches are bootstrap support values from 1000 replicates and only numbers above 50\% are shown. Scale bar is substitutions per site. The image was created using iTOL [84]

diverse suggesting that, particularly in some Toll subfamilies, there might exist different functions in the different insect lineages. Especially important is how this work shows that understanding Drosophila's Toll functions might not lead to the discovery of the same function in other species, even in other Diptera species. We show here how some Toll subfamilies are indeed extremely conserved, but others might have novel duplications which can lead to novel protein functions in specific lineages.

\section{Evolution of the intracytoplasmic gene families}

Studies that analyzed the different gene families involved in the fruit fly and mosquito immune system showed that there might be more gene duplications in the recognition and effector gene families when compared to those that participate in the different signaling cascades.
Some variation in copy number has been reported for Toll and Spatzle [60, 71, 72, 87], however, when intracellular members of the Toll pathway are regarded, only 1:1 orthologues have been described $[60,72,88]$. The presence of homologues of all these proteins in vertebrates indicates that this pathway is an ancient and efficient one $[18,28,89]$. Indeed, the presence of sequences of all four intracellular proteins in $D$. pulex's genome found here indicates that the genes were already present in the ancestral lineage to Pancrustacea. Nevertheless, modifications of the canonical pathway and the number of different functions it can perform already indicates great versatility $[29,38,90]$.

Most genomic studies of the intracytoplasmic insect proteins have been done using Diptera species, with only a few including different orders $[50,57,59,60,72,88,91-$ 93]. This bias has hidden some copy number variation 


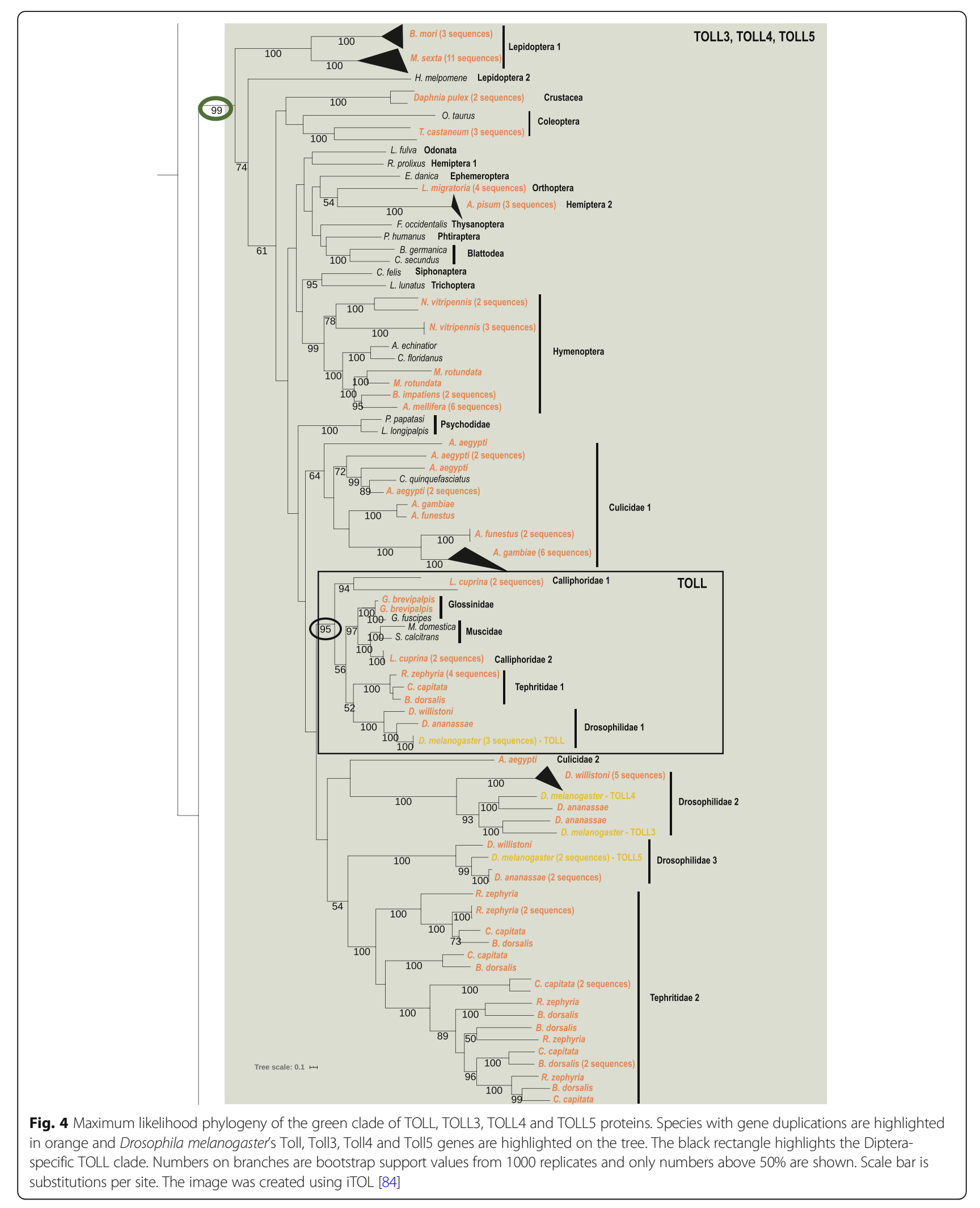




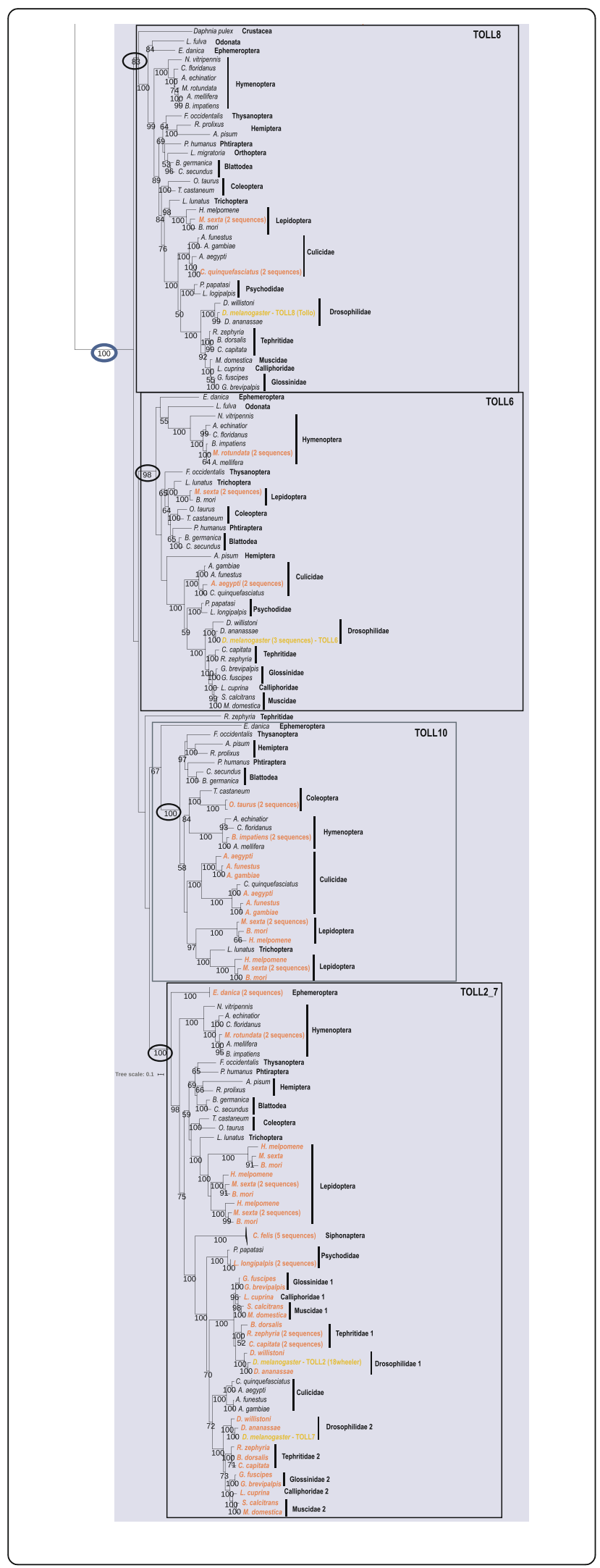

Fig. 5 Maximum likelihood phylogeny of the blue clade of TOLL2_7, TOLL6, TOLL8 and TOLL10 proteins. Species with gene duplications are highlighted in orange and Drosophila melanogaster's Toll2, Toll7, Toll6 and Toll8 genes are highlighted on the tree. The black rectangles highlight the clades where Drosophila's genes are found; The gray rectangle highlights the TOLL10 clade. Numbers on branches are bootstrap support values from 1000 replicates and only numbers above $50 \%$ are shown. Scale bar is substitutions per site. The image was created using iTOL [84]

among insect genomes. In this study, of the 39 insect genomes analyzed here, nine genomes have Pelle speciesspecific expansions, eight genomes for Tube, 17 genomes for Pellino and 11 genomes for MyD88 (Table 1 and Additional files 6, 7, 8 and 9). The presence of these gene duplications suggests new functions might be present in some species. After a duplication event, the gene copies can follow three main evolutionary paths [77, 94]: 1) neofuctionalization, where the new copy gains a new function; 2) subfunctionalization where the new copy can either split the same function with the ancestral one or even have the same function but in a different cell/body compartment or time in development; 3 ) or become a pseudogene. Gene duplication followed by subfunctionalization or neofunctionalization has been proposed as an important drive in the evolution of new gene functions [77, 9497]. In the evolution of the NOX gene family, for example, gene duplication followed by neofunctionalization happened very early in metazoan evolution since both the ability to produce superoxide and hydrogen peroxide were present in the ancestral calcium binding enzymes [98]. The importance of subfunctionalization in gene evolution has also been demonstrated. The vertebrate NOX gene family also has examples of subfunctionalization, where NOX2 seems to be expressed mostly in phagocytes whilst NOX1, NOX3 and NOX4 have other specific functions and patterns of subcellular localization and tissue distribution [99-101].

The Toll pathway was first described as part of the dorsal ventral patterning in Drosophila's development and, since then, many other developmental functions have been found [29]. During development, the perfect expression of genes at the right time and cell/body compartment is important and, in this light, the presence of species-specific duplications in Toll pathway genes might be of significance since these expansions observed here could mean neo or subfunctionalization events. Also, it has been proposed that morphological innovations can be based on differences of timing and location of expression and rewiring of existing gene networks or assembly of new networks with the developmental genes already present [102, 103]. Although most genomics studies so far have reported only one MyD88, Tube, Pelle and Pellino gene copy for insects [57, 59, 60, 71- 
$73,87,91-93,104,105]$, in this study, possibly due to the newer genome predictions and the thorough search methods, more genes were found, even for some wellstudied species (Table 1). Two copies of MyD88, for example, have also been found in the hemipteran, Nilaparvata lugens [106]. The new duplications seen here for many species and in elsewhere [106] may be redundant copies or be part of specific Toll signaling pathways, even of those that have not yet been described, since most occur in understudied species. More than one copy of Tube and Pelle were also found in other arthropod groups such as chelicerates (Ixodes scapularis) [71] and many Crustacea (Amphipoda, Isopoda and Decapoda) [107]. The presence of two copies of Pelle in Chelicerata and Crustacea and only one in Diptera lead Lai and Aboobaker [107] to speculate that this duplication might have occurred in the ancestral lineage to arthropods and was later lost in insects. As we can see here some insect species do have more than one copy of this gene, something that would give more support to their hypothesis. Nevertheless, in a phylogenetic framework it is possible to see here that almost all duplications fall, with high confidence, in species-specific clades and, therefore, do not indicate that the copies were present in an ancestral lineage.

An obvious insufficiency or excess of gene expansions among immune genes may reflect different selective pressures from different life environments derived from the diverse ecological niches of insects [60]. Here we analyze 13 insect orders, including holometabola and hemimetabola groups as well as species with diverse lifestyles such as blood feeding habits, for example; making an ideal background for comparing Toll pathway genes. The differences in gene expansion among the genomes can also be due to differences in development, an important function of Toll pathways, or ecological niche, responsible for which pathogens these species might encounter. With species-specific gene expansions, though, one can also argue that these duplication events might have happened very recently by chance and the gene copies could be on their way to becoming pseudogenes. If this is the case with some or all of these gene families' duplications it can only be determined through experimental laboratory work or population genomics analyses, where we can infer the role of the different evolutionary forces acting on these genes. If gene imbalance is not an issue here and the new copies are neutral, it is quite possible that there hasn't been enough time for these genes to be lost through random genetic drift. However, comparative analyses of gene losses according to gene ontology $(\mathrm{GO})$ categories have shown that the differences in dispensability observed between different genes might not be stochastic. GO terms related to signal transduction, immune response and other functions that are more sensitive to dosage imbalance are more prone to being lost [108]. These GO terms are less likely to be under the influence of random genetic drift and much more possibly to be under some kind of purifying or positive selection. Moreover, with duplications that have occurred in an ancestral lineage such as the ones found in some Toll subfamilies it is more likely that neofunctionalization or subfunctionalization events might have occurred.

\section{Evolution of TOLL gene family}

The time frame of insect lineage radiations is extremely old and, if dosage imbalance is not an issue, enough time would have passed for genetic drift to expunge or fix any neutral duplications that might have happened in the ancestral lineage of the different taxonomic groups. Hexapods first appeared 479 million years ago (MYA) and important radiation events seem to have happened due to ecologically driven differentiation greatly correlated to major developmental innovations [2, 109, 110]. In the Diptera's evolutionary history, for example, three main bursts of radiation events happened. In the first, 220 MYA, the ancestral lineages to Psychodidae and Culicidae first appeared, the second one then happened 180 MYA and, finally, a third one was 65 MYA, when most Schizophora lineages appeared [111]. The timing of these bursts of rapid radiations were so brief that in a phylogenetic framework the internal branches are usually very short due to limited information regarding the common evolutionary history of the different lineages. In many cases, such as the Holometabola lineages and other insect orders, internal branches also have higher amino acid substitution rates, further complicating matters [109]. This complicates analyses of ancient gene families where duplication events happened in the ancestral lineages of the groups being studied. The family of Toll receptors has an ancient evolutionary origin, 700 million years ago, being present in different metazoan groups [10, 20, 23, 24, 112]. Arthropod Tolls are homologous to vertebrate TLRs as both are transmembrane proteins with LRRs and a cytosolic TIR domain [23] and play an important role in the immune response in both taxonomic groups. Even though the signaling cascade is very similar with conserved homologues in arthropods and vertebrates, the number of TLRs in each group spans from two unrelated gene expansion events $[23,51$, 71]. Arthropod Tolls also do not seem to function as pattern recognition proteins as vertebrate TLRs do [113]. However, a report suggests that Toll7 does bind to VSV virus and induces antiviral autophagy through a noncanonical Toll pathway [114].

While many insect immunity studies have already shown that Toll copy number variation is common among different insect species [72, 87], the different 
evolutionary paths that each Toll subfamily seems to have been through were not discussed. In this study we found three major Toll phylogenetic clades that correspond to Toll subfamilies with distinctive evolutionary backgrounds that have not been discussed before (Fig. 2). Different studies have demonstrated the closer relationship of Arthropoda Toll9 genes with vertebrate TLRs $[71,72,115,116]$. Indeed, here the vertebrate-like Toll9 subfamily forms a highly supported clade and is the only insect subfamily where, like vertebrate TLRs, a single cysteine cluster is found in the $\mathrm{N}$-terminal region $[71,89]$. The Toll9 clade is further subdivided into three well supported clades (Fig. 3) and, interestingly, the presence of $1 \mathrm{~L}$. fulva (an Odonata) sequence in each of the three subclades found, suggests that three Toll9 genes might have been present in the Pterygota ancestor. Duplications of Toll9 were also found in the lepidopteran Plutella xylostella when its genome was characterized [117]. Although D. pulex is only found in the first subclade, Blattodea, Orthoptera and Lepidoptera sequences can be found in two subclades, whilst species from the other orders, including Diptera are only found in one. Since most insect studies have encompassed Diptera and only a few species from other orders, this subclade subdivision was missed in earlier studies. Due to the ancient evolutionary history of Tolls and the pattern of gene loss found for Toll9 here, where some orders are found only in different subclades, it is quite possible that three different genes were present in the ancestral lineage and some or all were differentially lost in some lineages. This subfamily shows lineage as well as species-specific expansions. In Diptera for example, most gene expansions are species-specific but in Culicidae there was a duplication that happened in the ancestral lineage leading to the Culex and Aedes genera. Big species-specific expansions happened in the Ephemeroptera E. danica and the Coleoptera $O$. taurus. Immunity related genes are frequently under the birth and death evolutionary model [118], where new genes are formed from gene duplications and others are lost due to the accumulation of deleterious mutations. This dynamic of gene gain and loss, in some cases, seems to be influenced by adaptation to new ecological niches and physiological changes during evolution [109], something that has happened many times in insect evolution.

In Hymenoptera no genes were found that belonged to the Toll9 subfamily. The evidence for gene loss is negative and can pass unnoticed or not be considered due to uncertainties in the completion or assembly of sequenced genomes. This can certainly be the case with Trichoptera, where only one species was analyzed and no Toll9 gene was found either. Nevertheless, six species of Hymenoptera belonging to different taxonomic families were analyzed here. The impact of gene loss in the evolution and function of surviving paralogues is not well investigated. It is easier to recognize gene duplication and the appearance of a new gene function as adaptive. However, it is also possible that the loss of a gene function altogether might not have a detrimental or adaptive effect on a species and, in fact, can be neutral $[108,119]$. Neutral or nearly neutral gene losses can be fixed in a species through genetic drift. Another possibility is the presence of other genes such as paralogs, analogs or even whole different pathways that serve the same or very similar functions and, therefore, the loss of a specific gene does not mean loss of function (mutation robustness). This can certainly be the case with Toll genes as a gene belonging to another subfamily may well have the same or similar function Toll9 was responsible for previously. The different functions each Toll subfamily gene has are still being discovered and it seems that, in some cases, functions do overlap [50, 120-122]. Toll receptors are an ancient gene family and thus their participation in different biochemical processes and patterns of gene gain and loss are expected. Another good example is the absence of NOX-art genes in Hymenoptera (among other insect orders as well) [123]. NOX is a gene family that first appeared in multicellular animals and, among their many roles, immunity is one of them. Some Hymenoptera species seem to have one order of magnitude higher rates of gene gain/loss than other insects mostly sprouting from single gene gain/loss in a large number of gene families [109].

In agreement with Palmer and Jiggins [71], that studied Toll genes in different arthropod lineages, no 1:1 orthologue was found for Toll (or Toll1) subfamily genes outside of Schizophora (Fig. 4). As such, and as seen for other arthropods [71], it is not possible to infer which Toll subfamily is responsible for immunity functions in other insect species other than Diptera. Also, since interior branches have low bootstrap values, it is difficult to say which, if any, of the other Drosophila's Tolls present in this clade (Toll3, Toll4 and Toll5) is the ancestral one. The high bootstrap value (100\%) suggests that Toll3 and Toll4 duplications happened in the Drosophilidae ancestral lineage (this study) and were lost in different degrees in the different Drosophila species [122]. These genes are under positive selective pressure in $D$. willinstoni and it was speculated that they might bind to new ligands other than Spatzle. These two genes seem to have lost their developmental functions since D. melanogaster knockdowns have little influence in viability [122]. These subfamilies are good examples of how some of the Toll pathway genes evolve, with duplication followed by positive selection in some cases or pseudonization in others. Other genomic studies of both vertebrates and invertebrates have already shown that Toll receptors have undergone diversification by mechanisms of genetic 
duplication, neofunctionalization, and subfunctionalization $[124,125]$. This diversification is possibly the reason the Toll family of proteins recognize a variety of extracellular and endosomal stimuli, participating in a number of different pathway responses.

In agreement with Levin and Malik [122] the subfamilies Toll8 and Toll6 seem to be conserved, with no lineage specific gene expansions and very few speciesspecific ones. Although Toll2_7 was also considered a conserved subfamily with $>90 \%$ amino acid identity among Drosophila species [122], extensive speciesspecific and lineage-specific expansions can be seen here especially in Lepidoptera and Diptera. The fact that studies so far mostly focused on Drosophila species or even Diptera have led to the belief that Toll genes evolve slowly and with little gene turnover (gain/losses), which would be consistent with their important roles in development and immunity. Nevertheless, even in this Toll clade where more conserved subfamilies are found (Toll8 and Toll6), various gene expansions suggest that, in some insect lineages at least, positive selection and new functions may have arisen. Especially for Toll2_7, gene gain and loss has happened on many occasions. A novel finding of this study, the Toll10 clade, seems to have been lost in Schizophora altogether and suggests how interchanging the Toll functions can be. The duplications of Toll2_7 in this lineage or any of the other duplications found in other Toll subfamilies could have the role Toll10 can perform in the other taxa. Although this is certainly possible, the SSN indicates that Toll10 is very dissimilar from other Drosophila Tolls and might have a different function (see Additional file 4). The Toll subfamilies phylogenetic tree and its pattern of gene gain/ loss found here and in the network analysis (see Additional file 4) indicates that homology-based methods of functional inference might not be accurate. Most functional studies have focused on Diptera so far (especially in D. melanogaster) and, therefore, understanding gene function in one species might not lead to discovering the same function in another, not even other Diptera species. Taking into account the evolutionary pattern and the lack of 1:1 orthology in most subfamilies, it is important that experiments with species from different taxonomic groups are performed in order to better understand gene function of the different Toll genes.

\section{Evolution of Spatzle gene family}

Although high divergence is found among the different Spatzle subfamilies, SSN analysis indicates that only for Spz1 and Spz7 an homology-based functional inference might be problematic. Even though a phylogenetic framework was not possible, network analysis shows that Spz1 is composed of a few taxa-specific iso-functional groups and Spz7 does not have any Diptera species and, therefore, no previously characterized functions (Fig. 1) (see also Additional file 5). A characteristic intron-exon structure found within a cysteine-knot in Spz, Spz2, Spz3, Spz5 genes suggests that these genes may have arisen by gene duplication events [55]. The presence of the cysteine residues needed for the 3D structure formation indicates that the Drosophila's homologues of Spatzle can also be activating ligands for Toll receptors [55, 126] and many different Toll/Spz interactions have also been demonstrated in the lab [90]. Nevertheless, the primary sequences of each Spatzle homolog found in Drosophila, and other insect species, are highly divergent. Within the different subfamilies, protein sequences show some degree of conservation (70-90\% sequence similarity among Drosophila sequences) [126], nevertheless, among the different subfamilies high divergence is observed $(20-40 \%)$ [55, 126]. Not surprisingly, previous works that have used distance tree building methods to better understand the evolution of the different Spatzle homologues in a few insect species have found low bootstrap support in internal branches [91, 126, 127].

Due to the high number of different species analyzed here, the low sequence similarity found among the Spatzle subfamilies prevented a phylogenetic reconstruction $(<30 \%)$, nevertheless, the SSN seemed to work well in defining the iso-functional groups (Fig. 1). Although this is not an evolutionary approach since it does not reconstruct the historical relationships among the sequences $[79,128]$, the groups recovered here are in agreement with the distance trees already published using fewer insect species [91, 126, 127]. The presence of sequences from most taxonomic groups within the iso-functional clusters in the SSN suggests that the duplication events that formed this protein family might have happened in the ancestral Pancrustacea, or multiple events of convergent evolution must have happened. Most $D$. pulex's sequences are highly divergent and compose a separate functional group but there are also sequences in the Spz3, Spz5, Spz6 and the new Spz7 cluster. Indeed, Wang and Zhu [126] analyzing only five insect orders (20 insect species, 12 of which were Drosophila) found 1:1 orthologues for each Spatzle subfamily. The downside to SSN is that the distinction between paralogues and orthologues is not possible [129] rendering it not feasible to determine if sequences have originated through species- or lineage-specific expansions.

Although network analysis only shows similarity between sequences it does use an amino acid substitution matrix model to compute these similarities and within the iso-functional groups one could argue that multiple substitutions are not an issue. In fact, this methodology is being used to help annotate uncharacterized proteins using identity levels with sequences of known function $[80,130]$. However, this methodology needs to be used 
with caution since paralogues that belong to the same iso-functional group might still have gone through subfunctionalization or another evolutionary process that renders them a different function albeit having low divergence. Our SSN analysis corroborates the trees constructed with distance algorithms, with Spz1 subfamily being more diverse (longer branches and low branch support) and with Spz3 and Spz4 subfamilies having higher similarity [91, 126, 127]. The SSN shows Spz3 and Spz4 belonging to the same functional group and Spz1 sequences in a less cohesive cluster, with Diptera species having lower identity values when compared to other insects (Fig. 1). Indeed, Drosophila Spz3 and Spz4 sequences have greater identity ( $51 \%$ similarity) when compared to sequences from the other subfamilies (20 to $38 \%$ ) [55]. In this study a new functional group composed of species from many taxonomic groups but without Diptera was also formed (Fig. 1) (see also Additional file 5) suggesting a previously unknown iso-functional group that might have been lost in Diptera. Although Sequence Similarity Networks (SSN) are not the same as a phylogenetic analysis it seems to work well for identifying functional groups within highly divergent protein families such as Spatzle as was demonstrated before for other families [128, 131, 132].

\section{Conclusion}

The increased number of available genomes is facilitating gene content and evolutionary analysis of many gene families. It is believed that only circa $50 \%$ of the proteins discovered through genome sequencing projects have correct functional annotation [133]. Here we analyzed different aspects of some protein families involved in the Toll pathway and, through computational methods, shed some light into their evolution and functional annotation. Our results show the importance of using as many species as possible, representing the different insect orders, to better understand gene content, origin and evolution in insects. The gene families analyzed in this study have an array of developmental and immune roles and the interaction between the different proteins seems to be of significance in the role they play. The joint use of phylogenetic and network methods works well, especially when highly divergent protein sequences are present within a family. The evolutionary patterns of many protein subfamilies found here indicate that homology-based methods of functional annotation might not be reliable in many cases. In a group as diverse and ancient as insects, phylogenetic and/or SSN investigations are necessary to better understand the different functional groups within a protein family. Our results suggest there is a subclade division within TOLL9 with three different genes that were probably present in the ancestral Pterygota lineage, with different patterns of gene gain and loss among the insect orders. We also show that the original Toll gene described and the TOLL2_7 clade are Diptera specific, indicating that functional inference from Diptera functional studies might not be readily transferable to species from other Orders. A new TOLL10 subclade with no Drosophila sequences was identified and we clearly show that the different TOLL subfamilies have divergent evolutionary histories that should be taken into consideration. We also show that events of gene gain in the intracellular gene families is pervasive and they mostly occur through species-specific expansions, suggesting the appearance of new functions in different species. The high number of insect species [39] analyzed here meant that species of public health and ecological importance were also investigated, and this can be of assistance when choosing specific genes to be used in new methodologies for pest and vector control. Finer, more species-specific methods of pest and vector control are essential to lessen the ecological impacts and health hazards these interventions usually have.

\section{Methods}

\section{Protein searches}

To search for all proteins involved in the Toll signaling pathway in the 40 arthropod genomes analyzed (39 Hexapoda and the Crustacea Daphnia pulex, Table 1), Hidden Markov Model (HMM) Profiles of each gene family were used as queries in HMMsearches [134] on the predicted protein sets using the FAT pipeline (developed by RD Mesquita). Profiles were retrieved from the Pfam database $[135,136]$. For Toll and MyD88, the Toll/interleukin-1 receptor (TIR) homology domain (HMM profile PF01582) was used. For Tube, the Tube Death Domain (DEATH_2) (PF14786) was used, and for Pelle both the protein kinase (Pkinase) and Death (DD) domains (PF00069 and PF00531) were used. Spatzle (PF16077) and Pellino (PF04710) domains were also used as queries. All proteins with significant E-value $(<$ 0.001 ) were retrieved and used as queries on BLASTp searches [137] against the manually curated Uniprot/ SwissProt protein database [138, 139], also using FAT. Since the sequences were searched on the predicted protein databases, whenever a specific protein was missing from a genome, Exonerate (protein2genome mode) [140] searches against the scaffolds of the whole genome were performed. For this step, the already predicted protein from the closest species available was used as query with the command line: exonerate - $\mathrm{m} \mathrm{p} 2 \mathrm{~g}$--showtargetgff -q ortologos.fasta $-\mathrm{t}$ scaffolds.fasta - -ryo " $>\% \mathrm{ti}$ (\%tab-\%tae) predicted by \%qi Strand \%g ID= \%pi Positives $=\%$ ps Raw_score $=\%$ s $\backslash$ n\%tcs $\backslash n$ " $>$ output_exonerate.txt. With these settings we could retrieve the coding sequences (CDS) of the genes searched, in the first 
reading frame, and then the newly predicted gene was translated using Transeq [141]. This search ensured that we could find genes that were not automatically predicted when they were present in the genomes. Also, partial gene sequences were also used as queries in tBLASTn searches against the NCBI Transcriptome Shotgun Assembly (TSA) database [142] in an attempt to retrieve a complete peptide for the subsequent phylogenetic analysis. The sequences of all peptides found and their accession numbers are available for download in FASTA format (see Additional files 10, 11, 12, 13, 14 and 15).

\section{Domain analysis}

The TIR domain is present both on Toll-like receptors and other signaling proteins $[51,113,143]$. In arthropods, it is also present in MyD88, an adaptor protein that participates in the Toll cascade, thus the HMMsearches were performed concomitantly. Nevertheless, to further investigate these two different proteins and work with genes with the same evolutionary background in further analysis, a characterization of the different domains in each protein was warranted. Also, for the protein kinase Pelle the search retrieved many nonspecific kinases that needed to be analyzed and the domain analysis helped sift through the HMM and BLASTp results. In any case, all proteins with significant E-values had their domain structure predicted using the CD-search batch tool $[144,145]$ and SMART $[146,147]$. Transmembrane helices and subcellular localization were predicted with TMHMM and TargetP [148], respectively. Among the proteins found, only those with the expected domains, regions and sizes were used in the phylogenetic analyses.

\section{Sequence similarity networks (SSNs)}

The collection of protein sequences extracted with TIR and Spatzle Pfam domains from all 40 genomes analyzed were used to construct sequence similarity networks (SSNs). SSN is a methodology used to summarize protein-protein similarities on a large scale $[80,81]$ and, therefore, we decided to first investigate all proteins obtained with these domains with this methodology. Especially for the TIR domain, where it was expected that more than one functional protein family could have been found on the HMMsearches, the use of the SSN made it possible to separate the different functional and orthologous groups. Also, with this methodology, sequences that could not be used in the multiple alignments and phylogenetic analyses due to small sizes and incomplete prediction could be investigated as well since this is mainly an all-by-all BLASTp pairwise sequence analysis $[79,80]$. Although not a global alignment, newer versions of BLAST do extend the alignment and take gaps into account when computing alignment scores. On top of the two Pfam domains, we also used a smaller sequence set of only Toll-like proteins to better understand the functional groups within this protein family. The complete protein sequences were used in all three SSNs and different threshold values were tested for each protein set. SSNs have been shown to work well in identifying functional groups and revealing outliers [79]. The Enzyme Function Initiative - Enzyme Similarity Tool [80, 81, 131, 149] was used to cluster the sequences using user defined similarity thresholds. Here each node in the network represents proteins with $100 \%$ sequence identity and the edges represent the similarity between the nodes. The threshold defines the number of edges since an edge is drawn between nodes only if the BLAST pairwise similarity score between them is above the threshold value defined. The alignment score (threshold) used to restrict the all-by-all BLASTs in all three networks varied. Differently from a normal BLAST result, EFI-EST alignment score is not dependent on database size [80]. For each gene family it was chosen based on the percent identity versus alignment score quartile plot with a $40 \%$ identity threshold as advised by the authors. The SSNs were visualized using the Organic layout (Wiese yFiles) in Cytoscape 3.6.1 [150] where relevant information for each sequence was also mapped (taxonomy, Swissprot results, domain information, functional annotation). OrthoMCL 1.4 [151] results with a cut off $P$-value of $1 \mathrm{E}$-05 were also used as a guide for Spatzle orthologous group formation.

\section{Phylogenetic analysis}

Amino acid sequences of the proteins retrieved by our searches were aligned locally with PASTA [152] using mafft [153] and a Jones Taylor Thornton (JTT) matrix [154]. The alignments were visualized and converted to Phylip format using the software SeaView [155]. The same program was used to trim the sequences leaving only the region containing the TIR domain for Toll proteins. This way, the variable regions containing the cysteine knots and LRR were eliminated from the alignment. This trimmed version of the alignment for Toll and the whole alignment for MyD88, Tube, Pelle and Pellino were then used to construct phylogenetic trees for each gene family using the maximum likelihood method with RAxML [156] on CIPRES [157]. The amino acid JTT scoring matrix was used [154] and bootstrap analysis with 1000 replicates was performed to infer branch support. Visualization and further editing of the trees was performed on the web tool iTOL [84]. Since Hexapoda is phylogenetically closer to Crustacea $[1,74]$, more specifically to the Branchiopoda [158], and the most recent Arthropoda Toll pathway evolutionary gene study has 
used $D$. pulex in their analysis [71] we decided to use this species as the outgroup.

\section{Supplementary Information}

The online version contains supplementary material available at https://doi. org/10.1186/s12864-021-07886-7.

Additional file 1. List of genes found with Exonerate. Species name, scaffold and genomic region where they were found and if they were used in the phylogenetic analyses.

Additional file 2. Text file, in FASTA format, with protein sequences found with Exonerate Searches and translated with Transeq.

Additional file 3. Figure in TIFF format with the SSN of the TIR domain proteins found on FAT searches. Each node represents proteins sharing $100 \%$ sequence similarity and edges represent an alignment score cut-off of 20 between proteins. The nodes are colored based on Toll (magenta) and MyD88 (teal) functional groups.

Additional file 4. SSN of only TOLL 1 genes (from Additional file 3). Each node represents proteins sharing 100\% sequence similarity. The network was created using an alignment score cut-off of 20 and, in Cytoscape, an identity value of $50 \%$ was also used as threshold and edges with lower values were deleted. The nodes are colored based on taxonomic groups (see legend). and edges represent an alignment score cut-off of 20 between proteins. Protein names within the figure depict Drosophila melanogaster's known genes that are represented in triangled shaped nodes.

Additional file 5. SSN of the Spatzle domain proteins found on FAT searches. Each node represents proteins sharing 100\% sequence similarity and edges with an alignment score cut-off of 30 between proteins. A) Nodes are colored based on taxonomic groups and B) with only Daphnia pulex nodes highlighted in green.

Additional file 6. Maximum likelihood phylogeny of aligned Tube proteins. The blue square highlights Hexapoda species and the species with gene duplications are highlighted in orange. Numbers on branches are bootstrap support values from 1000 replicates, only numbers above $50 \%$ are shown. Scale bar is substitutions per site. The image was created using iTOL.

Additional file 7. Maximum likelihood phylogeny of aligned Pellino proteins. The blue square highlights Hexapoda species and the species with gene duplications are highlighted in orange. Numbers on branches are bootstrap support values from 1000 replicates, only numbers above

$50 \%$ are shown. Scale bar is substitutions per site. The image was created using $\mathrm{TTOL}$

Additional file 8. Maximum likelihood phylogeny of aligned Pelle proteins. The blue square highlights Hexapoda species and the species with gene duplications are highlighted in orange. Numbers on branches are bootstrap support values from 1000 replicates, only numbers above $50 \%$ are shown. Scale bar is substitutions per site. The image was created using $\mathrm{TTOL}$

Additional file 9. Maximum likelihood phylogeny of aligned MyD88 proteins. The blue square highlights Hexapoda species and the species with gene duplications are highlighted in orange. Numbers on branches are bootstrap support values from 1000 replicates, only numbers above $50 \%$ are shown. Scale bar is substitutions per site. The image was created using iTOL.

Additional file 10. Text files, in FASTA format, with protein sequences found with FAT searches of Tube.

Additional file 11. Text files, in FASTA format, with protein sequences found with FAT searches of Pellino.

Additional file 12. Text files, in FASTA format, with protein sequences found with FAT searches of Pelle.

Additional file 13. Text files, in FASTA format, with protein sequences found with FAT searches of MyD88.

Additional file 14. Text files, in FASTA format, with protein sequences found with FAT searches of Toll.
Additional file 15. Text files, in FASTA format, with protein sequences found with FAT searches of Spatzle.

\section{Acknowledgements}

To RM Albano, for a critical reading of the manuscript. This work was part of the PhD thesis of L Lima at the Computational and Systems Biology program at Oswaldo Cruz Institute - Fiocruz.

\section{Authors' contributions}

RS, RDM, RJ - Design the work; RS, LFL - generated the datasets and results; $\mathrm{RS}$, LFL, RDM, RJ - analyzed results and discussed conclusions; RS- wrote the first draft of the manuscript. All authors read and approved the final manuscript.

\section{Funding}

This study was financed in part by the Coordenação de Aperfeiçoamento de Pessoal de Nível Superior - Brasil (CAPES) - Finance Code 001; as a PhD scholarship to LF Lima. All authors are part of Instituto Nacional de Ciência e Tecnologia em Entomologia Molecular - INCT-EM.

\section{Availability of data and materials}

All data generated or analyzed during this study are included in this published article [see Additional files 1, 2, 3, 4, 5, 6, 7, 8, 9, 10, 11, 12, 13, 14 and 15). The FASTA files with the sequences used can also be retrieved in https://www.dropbox.com/sh/lkksoj542qn6kqj/AAB3pKV2A38bY2cCtX3 i7AJxa?dl=0

\section{Declarations}

Ethics approval and consent to participate

Not applicable.

\section{Consent for publication}

Not applicable.

\section{Competing interests}

The authors declare that they have no competing interests.

\section{Author details}

${ }^{1}$ Laboratório de Biologia Computacional e Sistemas, Oswaldo Cruz Foundation, Fiocruz, Rio de Janeiro, Brazil. '2Laboratório de Bioinformática, Instituto de Química, Universidade Federal do Rio de Janeiro, Rio de Janeiro, Brazil. ${ }^{3}$ Instituto Nacional de Ciência e Tecnologia em Entomologia Molecular-INCT-EM, Rio de Janeiro, Brazil.

Received: 7 April 2021 Accepted: 13 July 2021

Published online: 21 July 2021

References

1. Engel MS. Insect evolution. Curr Biol. 2015;25(19):R868-72.

2. Edgecombe GD. Arthropod phylogeny: an overview from the perspectives of morphology, molecular data and the fossil record. Arthropod Struct Dev. 2010:39(2-3):74-87.

3. Giribet G, Edgecombe GD. Reevaluating the arthropod tree of life. Annu Rev Entomol. 2012:57:167-86

4. Mayhew PJ. Why are there so many insect species? Perspectives from fossils and phylogenies. Biol Rev Camb Philos Soc. 2007:82(3):425-54.

5. Hill DS. The Economic Importance of Insects; 1997. p. 399.

6. Bradshaw CJ, Leroy B, Bellard C, Roiz D, Albert C, Fournier A, et al. Massive yet grossly underestimated global costs of invasive insects. Nat Commun. 2016;7:12986.

7. Dantas-Torres F, Chomel BB, Otranto D. Ticks and tick-borne diseases: a one Helath perspective. Trends Parasitol. 2012;28(10):437-46.

8. Smith MR, Singh GM, Mozaffarian D, Myers SS. Effects of decreases of animal pollinators on human nutrition and global health: a modelling analysis. Lancet. 2015:386(10007):1964-72.

9. Liere $H$, Jha S, Philpott SM. Intersection between biodiversity conservation, agroecology, and ecosystem services. Agroecol Sustain Food Syst. 2017; 41(7):723-60. 
10. Lemaitre B, Hoffmann J. The host defense of Drosophila melanogaster Annu Rev Immunol. 2007;25:697-743.

11. Imler JL. Overview of Drosophila immunity: a historical perspective. Dev Comp Immunol. 2014;42(1):3-15.

12. Marques JT, Imler JL. The diversity of insect antiviral immunity: insights from viruses. Curr Opin Microbiol. 2016;32:71-6.

13. Cooper D, Eleftherianos I. Memory and specificity in the insect immune system: current perspectives and future challenges. Front Immunol. 2017;8: 539 .

14. Dhinaut J, Chogne M, Moret Y. Immune priming specificity within and across generations reveals the range of pathogens affecting evolution of immunity in an insect. J Anim Ecol. 2018;87(2):448-63.

15. Sheehan G, Farrell G, Kavanagh K. Immune priming: the secret weapon of the insect world. Virulence. 2020;11(1):238-46.

16. Sheehan G, Garvey A, Croke M, Kavanagh K. Innate humoral immune defences in mammals and insects: the same, with differences? Virulence. 2018;9(1):1625-39.

17. Kumar A, Srivastava P, Sirisena P, Dubey SK, Kumar R, Shrinet J, et al. Mosquito innate immunity. Insects. 2018;9(3):95.

18. Vilmos $P$, Kurucz E. Insect immunity: evolutionary roots of the mammalian innate immune system. Immunol Lett. 1998;62:59-66.

19. Strand MR. The insect cellular immune response. Insect Sci. 2008;15:1-14.

20. Hoffman JA, Kafatos FC, Janeway CA, Ezekowitz RAB. Phylogenetic perspectives in innate immunity. Science. 1999;284:1313-8.

21. Imler JL, Ferrandon D, Royet J, Reichhart JM, Hetru C, Hoffmann JA. Tolldependent and toll-independent immune responses in Drosophila. J Endotoxin Res. 2004;10(4):241-6.

22. Kimbrell DA, Beutler B. The evolution and genetics of innate immunity. Nat Rev Genet. 2001;2:256-67.

23. Leulier F, Lemaitre B. Toll-like receptors--taking an evolutionary approach. Nat Rev Genet. 2008:9(3):165-78.

24. Medzhitov R, Janeway CA. Decoding the patterns of self and nonself by innate immune system. Science. 2002;296:298-300.

25. Sabin LR, Hanna SL, Cherry S. Innate antiviral immunity in Drosophila. Curr Opin Immunol. 2010;22(1):4-9.

26. Obbard DJ, Gordon KH, Buck AH, Jiggins FM. The evolution of RNAi as a defence against viruses and transposable elements. Philos Trans R Soc Lond Ser B Biol Sci. 2009;364(1513):99-115.

27. Valanne S, Kallio J, Kleino A, Ramet M. Large-scale RNAi screens add both clarity and complexity to Drosophila NF-kappaB signaling. Dev Comp Immunol. 2012;37(1):9-18.

28. Valanne S, Wang JH, Ramet M. The Drosophila toll signaling pathway. J Immunol. 2011;186(2):649-56.

29. Lindsay SA, Wasserman SA. Conventional and non-conventional Drosophila toll signaling. Dev Comp Immunol. 2014;42(1):16-24.

30. Gilmore TD, Wolenski FS. NF-kB: where did it come from and why? Immunol Rev. 2012;246:14-35.

31. Akira S, Uematsu S, Takeuchi O. Pathogen recognition and innate immunity. Cell. 2006;124(4):783-801.

32. Charroux B, Rival T, Narbonne-Reveau K, Royet J. Bacterial detection by Drosophila peptidoglycan recognition proteins. Microbes Infect. 2009;11(67):631-6.

33. Dziarski R. Peptidoglycan recognition proteins (PGRPs). Mol Immunol. 2004; 40(12):877-86

34. Wang S, Beerntsen BT. Functional implications of the peptidoglycan recognition proteins in the immunity of the yellow fever mosquito, Aedes aegypti. Insect Mol Biol. 2015;24(3):293-310.

35. Michel T, Reichhart JM, Hoffman JA, Royet J. Drosophila toll activated by gram-positive bacteria through a circulating peptidoglycan recognition protein. Lett Nat. 2001;414:756-9.

36. Anderson KV, Jurgens G, Nusslein-Volhard C. Establishment of dorsal-ventral polarity in the Drosophila embryo: genetic studies on the role of the toll gene product. Cell. 1985;42:779-89.

37. Belvin M, Anderson KV. A conserved signaling pathway: the Drosophila tolldorsal pathway. Annu Rev Cell Dev Biol. 1996;12:393-416.

38. Shaukat Z, Liu D, Gregory S. Sterile inflammation in Drosophila. Mediat Inflamm. 2015:2015:369286.

39. Weber AN, Gangloff M, Moncrieffe MC, Hyvert Y, Imler JL, Gay NJ. Role of the Spatzle pro-domain in the generation of an active toll receptor ligand. J Biol Chem. 2007;282(18):13522-31.
40. Parthier C, Stelter M, Ursel C, Fandrich U, Lilie H, Breithaupt C, et al. Structure of the toll-Spatzle complex, a molecular hub in Drosophila development and innate immunity. Proc Natl Acad Sci U S A. 2014;111(17): 6281-6.

41. Hu X, Yagi Y, Tanji T, Zhou S, Ip YT. Multimerization and interaction of toll and Spatzle in Drosophila. Proc Natl Acad Sci U S A. 2004;101(25):9369-74.

42. Weber AN, Tauszig-Delamansure S, Hoffman JA, Lelièvre E, Gascan H, Ray $\mathrm{KP}$, et al. Binding of the Drosophila cytokine Spatzle to toll is direct and establishes signalling. Nat Immunol. 2003;4(8):794-800.

43. Horng T, Medzhitov R. Drosophila MyD88 is an adapter in the toll signaling pathway. Proc Natl Acad Sci U S A. 2001;98(22):12654-8.

44. Goto A, Imler JL. Toll signaling in flies and mammals: two sorts of MyD88. Immunity. 2012;36(4):555-7.

45. Kagan JC, Medzhitov R. Phosphoinositide-mediated adaptor recruitment controls toll-like receptor signaling. Cell. 2006;125(5):943-55.

46. Marek LR, Kagan JC. Phosphoinositide binding by the toll adaptor dMyD88 controls antibacterial responses in Drosophila. Immunity. 2012;36(4):612-22.

47. Sun H, Bristow BN, Qu G, Wasserman SA. A heterotrimeric death domain complex in toll signaling. Proc Natl Acad Sci U S A. 2002;99(20):12871-6.

48. Sun H, Towb P, Chiem DN, Foster BA, Wasserman SA. Regulated assembly of the toll signaling complex drives Drosophila dorsoventral patterning. EMBO J. 2004;23(1):100-10

49. Haghayeghi A, Sarac A, Czerniecki S, Grosshans J, Schock F. Pellino enhances innate immunity in Drosophila. Mech Dev. 2010;127(5-6):301-7.

50. Tauszig S, Jouanguy E, Hoffmann JA, Imler JL. Toll-related receptors and the control of antimicrobial peptide expression in Drosophila. Proc Natl Acad Sci U S A. 2000;97(19):10520-5.

51. Imler JL, Zheng L. Biology of toll receptors: lessons from insects and mammals. J Leukoc Biol. 2003;75(1):18-26.

52. Botos I, Segal DM, Davies DR. The structural biology of toll-like receptors. Structure. 2011;19(4):447-59.

53. Gangloff M, Weber AN, Gibbard RJ, Gay NJ. Evolutionary relationships, but functional differences, between the Drosophila and human toll-like receptor families. Biochem Soc Trans. 2003:31:660-3.

54. Gay NJ, Gangloff M. Structure and function of toll receptors and their ligands. Annu Rev Biochem. 2007;76:141-65.

55. Parker JS, Mizuguchi K, Gay NJ. A family of proteins related to Spatzle, the toll receptor ligand, are encoded in the Drosophila genome. Proteins Struct Funct Genet. 2001;45:71-80.

56. Rock FL, Hardiman G, Timans JC, Kastelein RA, Bazan JF. A family of human receptors structurally related to Drosophila toll. Proc Natl Acad Sci. 1998;95: 588-93.

57. Zou Z, Evans JD, Lu Z, Zhao P, Williams M, Sumathipala $N$, et al. Comparative genomic analysis of the Tribolium immune system. Genome Biol. 2007;8(8):R177.

58. Cheng TC, Zhang YL, Liu C, Xu PZ, Gao ZH, Xia QY, et al. Identification and analysis of toll-related genes in the domesticated silkworm, Bombyx mori. Dev Comp Immunol. 2008;32(5):464-75.

59. Evans JD, Aronstein K, Chen YP, Hetru C, Imler JL, Jiang H, et al. Immune pathways and defence mechanisms in honey bees Apis mellifera. Insect Mol Biol. 2006:12(5):645-56

60. Christophides GK, Zdobnov EM, Barillas-Mury C, Birney E, Blandin S, Blass C, et al. Immunity-related genes and gene families in Anopheles gambiae. Science. 2002;298:159-65.

61. Nonaka S, Kawamura K, Hori A, Salim E, Fukushima K, Nakanishi Y, et al. Characterization of Spz5 as a novel ligand for Drosophila Toll-1 receptor. Biochem Biophys Res Commun. 2018;506(3):510-5.

62. Gangloff M, Murali A, Xiong J, Arnot CJ, Weber AN, Sandercock AM, et al. Structural insight into the mechanism of activation of the toll receptor by the dimeric ligand Spatzle. J Biol Chem. 2008;283(21):14629-35.

63. Jang $\mathrm{H}$, Chosa N, Kim SH, Nam HJ, Lemaitre B, Ochiai M, et al. A Spatzleprocessing enzyme required for toll signaling activation in Drosophila innate immunity. Dev Cell. 2006:10(1):45-55.

64. Lewis M, Arnot CJ, Beeston H, McCoy A, Ashcroft AE, Gay NJ, et al. Cytokine Spatzle binds to the Drosophila immunoreceptor toll with a neurotrophinlike specificity and couples receptor activation. Proc Natl Acad Sci U S A. 2013;110(51):20461-6.

65. DeLotto Y, DeLotto R. Protelytic processing of the Drosophila Spatzle protein by Easter generates a dimeric NGF-like molecule with ventralising activity. Mech Dev. 1998;72:141-8. 
66. Arnot CJ, Gay NJ, Gangloff M. Molecular mechanism that induces activation of Spatzle, the ligand for the Drosophila toll receptor. J Biol Chem. 2010; 285(25):19502-9.

67. Alpar L, Bergantinos $C$, Johnston LA. Spatially restricted regulation of Spatzle/ toll signaling during cell competition. Dev Cell. 2018;46(6):706-19 e5.

68. Mulinari S, Hacker U, Castillejo-Lopez C. Expression and regulation of Spatzle-processing enzyme in Drosophila. FEBS Lett. 2006;580(22): 5406-10.

69. Ligoxygakis P, Pelte N, Hoffman JA, Reichhart JM. Activation of Drosophila toll during fungal infection by blood serine protease. Science. 2002;297:114-6.

70. Issa N, Guillaumot N, Lauret E, Matt N, Schaeffer-Reiss C, Van Dorsselaer A, et al. The circulating protease Persephone is an immune sensor for microbial Proteolytic activities upstream of the Drosophila toll pathway. Mol Cell. 2018;69(4):539-50 e6.

71. Palmer WJ, Jiggins FM. Comparative genomics reveals the origins and diversity of arthropod immune systems. Mol Biol Evol. 2015;32(8):2111-29.

72. Waterhouse RM, Kriventseva EV, Meister S, Zi Z, Alvarez KS, Bartholomay LC, et al. Evolutionary dynamics of immune-related genes and pathways in disease-vector mosquitoes. Science. 2007:316(5832):1538-743.

73. Gerardo NM, Altincicek B, Anselme C, Atamian H, Barribeau SM, Vos M, et al. Immunity and other defenses in pea aphids, Acyrthosiphon pisum. Genome Biol. 2010;11:R21. https://doi.org/10.1186/gb-2010-11-2-r21.

74. Misof B, Liu S, Meusemann K, Peters RS, Donath A, Mayer C, et al. Phylogenomics resolves the timing and pattern of insect evolution. Science. 2014;346(6210):763-7.

75. Reidenbach KR, Cook S, Bertone MA, Harbach RE, Wiegmann BM, Besansky NJ. Phylogenetic analysis and temporal diversification of mosquitoes (Diptera: Culicidae) based on nuclear genes and morphology. BMC Evol Biol. 2009;9:298.

76. Gaunt MW, Miles MA. An insect molecular clock dates the origin of the insects and accords with palaeontological and biogeographic landmarks. Mol Biol Evol. 2002;19(5):748-61.

77. Dittmar K, Liberles D. Evolution after gene duplication. Hoboken: WileyBlackwell; 2010. p. 329.

78. Trautwein MD, Wiegmann BM, Beutel R, Kjer KM, Yeates DK. Advances in insect phylogeny at the dawn of the postgenomic era. Annu Rev Entomol. 2012;57:449-68.

79. Atkinson HJ, Morris JH, Ferrin TE, Babbitt PC. Using sequence similarity networks for visualization of relationships across diverse protein superfamilies. PLoS One. 2009:4(2):e4345.

80. Gerlt JA, Bouvier JT, Davidson DB, Imker HJ, Sadkhin B, Slater DR, et al. Enzyme function initiative-enzyme similarity tool (EFI-EST): a web tool for generating protein sequence similarity networks. Biochim Biophys Acta. 2015;1854(8):1019-37.

81. Gerlt JA. Genomic enzymology: web tools for leveraging protein family sequence-function space and genome context to discover novel functions. Biochemistry. 2017;56(33):4293-308.

82. Rost B. Twilight zone of protein sequence alignment. Protein Eng. 1999; 12(2):85-94

83. Cantarel BL, Morrison HG, Pearson W. Exploring the relationship between sequence similarity and accurate phylogenetic trees. Mol Biol Evol. 2006; 23(11):2090-100

84. Letunic I, Bork P. Interactive tree of life (iTOL) v4: recent updates and new developments. Nucleic Acids Res. 2019;47(W1):W256-W9.

85. Kjer KM, Simon C, Yavorskaya M, Beutel RG. Progress, pitfalls and parallel universes: a history of insect phylogenetics. J R Soc Interface. 2016;13(121): 20160363.

86. Denton JF, Lugo-Martinez J, Tucker AE, Schrider DR, Warren WC, Hahn MW. Extensive error in the number of genes inferred from draft genome assemblies. PLoS Comput Biol. 2014;10(12):e1003998.

87. Viljakainen L. Evolutionary genetics of insect innate immunity. Brief Funct Genomics. 2015;14(6):407-12

88. Sackton TB, Lazzaro BP, Schlenke TA, Evans JD, Hultmark D, Clark AG. Dynamic evolution of the innate immune system in Drosophila. Nat Genet. 2007;39(12):1461-8.

89. Brennan JJ, Gilmore TD. Evolutionary origins of toll-like receptor signaling. Mol Biol Evol. 2018;35(7):1576-87.

90. Chowdhury M, Li CF, He Z, Lu Y, Liu XS, Wang YF, et al. Toll family members bind multiple Spatzle proteins and activate antimicrobial peptide gene expression in Drosophila. J Biol Chem. 2019;294(26):10172-81. https://doi. org/10.1074/jbc.RA118.006804.
91. Liu Y, Shen D, Zhou F, Wang G, An C. Identification of immunity-related genes in Ostrinia furnacalis against entomopathogenic fungi by RNA-seq analysis. PLoS One. 2014;9(1):e86436.

92. Tanaka H, Ishibashi J, Fujita K, Nakajima Y, Sagisaka A, Tomimoto K, et al. A genome-wide analysis of genes and gene families involved in innate immunity of Bombyx mori. Insect Biochem Mol Biol. 2008;38(12):1087-110.

93. Cao X, He Y, Hu Y, Wang Y, Chen YR, Bryant B, et al. The immune signaling pathways of Manduca sexta. Insect Biochem Mol Biol. 2015;62:64-74.

94. Zhang J. Evolution by gene duplication: an update. Trends Ecol Evol. 2003; 18(6):292-8.

95. Roth C, Rastogi S, Arvestad L, Dittmar K, Light S, Ekman D, et al. Evolution after gene duplication: models, mechanisms, sequences, systems, and organisms. J Exp Zool B Mol Dev Evol. 2007;308(1):58-73.

96. Magadum S, Banerjee U, Murugan P, Gangapur D, Ravikesavan R. Gene duplication as a major force in evolution. J Genet. 2013;92:155-61.

97. Santos EM, Bouquin A, Crumière AJJ, Khila A. Taxon-restricted genes at the origin of a novel trait allowing access to a new environment. Science. 2017; 358:386-90

98. Zhang X, Krause KH, Xenarios I, Soldati T, Boeckmann B. Evolution of the ferric reductase domain (FRD) superfamily: modularity, functional diversification, and signature motifs. PLoS One. 2013:8(3):e58126.

99. Bokoch GM, Knaus UG. NADPH oxidases: not just for leukocytes anymore! Trends Biochem Sci. 2003;28(9):502-8.

100. Manea SA, Constantin A, Manda G, Sasson S, Manea A. Regulation of Nox enzymes expression in vascular pathophysiology: focusing on transcription factors and epigenetic mechanisms. Redox Biol. 2015;5:358-66.

101. Lambeth JD, Neish AS. Nox enzymes and new thinking on reactive oxygen: a double-edged sword revisited. Annu Rev Pathol. 2014;9:119-45.

102. Hoekstra HE, Coyne JA. The locus of evolution: evo devo and the genetics of adaptation. Evolution. 2007:61(5):995-1016.

103. Davidson EH, Erwin DH. Gene regulatory networks and the evolution of animal body plans. Science. 2006:311(5762):796-800.

104. Adams MD, Celniker SE, Holt RA, Evans CA, Gocayne JD, Amanatides PG, et al. The genome sequence of Drosophila melanogaster. Science. 2000; 287(5461):2185-95.

105. McTaggart SJ, Conlon C, Colbourne JK, Blaxter ML, Little TJ. The components of the Daphnia pulex immune system as revealed by complete genome sequencing. BMC Genomics. 2009:10:175.

106. Bao YY, Qu LY, Zhao D, Chen LB, Jin HY, Xu LM, et al. The genome- and transcriptome-wide analysis of innate immunity in the brown planthopper, Nilaparvata lugens. BMC Genomics. 2013;14:160.

107. Lai $A G$, Aboobaker AA. Comparative genomic analysis of innate immunity reveals novel and conserved components in crustacean food crop species. BMC Genomics. 2017;18(1):389.

108. Albalat R, Cañestro C. Evolution by gene loss. Nat Rev Genet. 2016;17(7): 379-91.

109. Thomas GWC, Dohmen E, Hughes DST, Murali SC, Poelchau M, Glastad K, et al. Gene content evolution in the arthropods. Genome Biol. 2020;21(1):15

110. Rota-Stabelli O, Daley AC, Pisani D. Molecular timetrees reveal a Cambrian colonization of land and a new scenario for ecdysozoan evolution. Curr Biol. 2013;23(5):392-8.

111. Wiegmann BM, Trautwein MD, Winkler IS, Barr NB, Kim JW, Lambkin C, et al. Episodic radiations in the fly tree of life. Proc Natl Acad Sci U S A. 2011; 108(14):5690-5.

112. Hoffman JA, Reichhart JM. Drosophila innate immunity: an evolutionary perspective. Nat Immunol. 2002;3(2):121-6.

113. Imler JL, Hoffman JA. Toll receptors in innate immunity. Trends Cell Biol. 2001;11(7):304-11.

114. Nakamoto M, Moy RH, Xu J, Bambina S, Yasunaga A, Shelly SS, et al. Virus recognition by Toll-7 activates antiviral autophagy in Drosophila. Immunity. 2012;36(4):658-67.

115. Wu S, Zhang X, Chen X, Cao P, Beerntsen BT, Ling E. BmToll9, an arthropod conservative toll, is likely involved in the local gut immune response in the silkworm, Bombyx mori. Dev Comp Immunol. 2010;34(2):93-6.

116. Liu G, Zhang H, Zhao C, Zhang H. Evolutionary history of the toll-like receptor gene family across vertebrates. Genome Biol Evol. 2020;12(1):3615-34.

117. Xia X, Yu L, Xue M, Yu X, Vasseur L, Gurr GM, et al. Genome-wide characterization and expression profiling of immune genes in the diamondback moth, Plutella xylostella (L.). Sci Rep. 2015;5:9877.

118. Nei M, Rooney AP. Concerted birth-and-death evolution of gene multigene families. Annu Rev Genet. 2005;39:121-52. 
119. Porter ML, Crandall KA. Lost along the way: the significance of evolution in reverse. Trends Ecol Evol. 2003;18(10):541-7.

120. Yagi Y, Nishida Y, Ip YT. Functional analysis of Toll-related genes in Drosophila. Dev Growth Differ. 2010;52:771-83.

121. Kambris Z, Hoffman JA, Imler JL, Capovilla M. Tissue and stage-specific expression of the tolls in Drosophila embryos. Gene Expr Patterns. 2002;2:311-7.

122. Levin TC, Malik HS. Rapidly evolving Toll-3/4 genes encode male-specific toll-like receptors in Drosophila. Mol Biol Evol. 2017;34(9):2307-23.

123. Gandara ACP, Torres A, Bahia AC, Oliveira PL, Schama R. Evolutionary origin and function of NOX4-art, an arthropod specific NADPH oxidase. BMC Evol Biol. 2017;17(1):92.

124. Huang HR, Chen ZJ, Kunes S, Chang GD, Maniatis T. Endocytic pathway is required for Drosophila toll innate immune signaling. Proc Natl Acad Sci U S A. 2010;107(18):8322-7.

125. Roach JM, Racioppi L, Jones CD, Masci AM. Phylogeny of toll-like receptor signaling: adapting the innate response. PLoS One. 2013;8(1):e54156.

126. Wang Y, Zhu S. Evolutionary and functional epitopes of the Spatzle protein: new insights into activation of the toll receptor. Cell Mol Life Sci. 2009;66(9): 1595-602.

127. An C, Jiang H, Kanost MR. Proteolytic activation and function of the cytokine Spatzle in the innate immune response of a lepidopteran insect, Manduca sexta. FEBS J. 2010;277(1):148-62.

128. Copp JN, Anderson DW, Akiva E, Babbitt PC, Tokuriki N. Exploring the sequence, function, and evolutionary space of protein superfamilies using sequence similarity networks and phylogenetic reconstructions. Methods Enzymol. 2019;620:315-47.

129. Pearson WR. An introduction to sequence similarity ("homology") searching. Curr Protoc Bioinformatics. 2013;3:3-1.

130. Tian W, Skolnick J. How well is enzyme function conserved as a function of pairwise sequence similarity? J Mol Biol. 2003;333(4):863-82.

131. Zallot R, Oberg N, Gerlt JA. The EFI web resource for genomic enzymology tools: leveraging protein, genome, and Metagenome databases to discover novel enzymes and metabolic pathways. Biochemistry. 2019;58(41):4169-82.

132. Copp JN, Akiva E, Babbitt PC, Tokuriki N. Revealing unexplored sequencefunction space using sequence similarity networks. Biochemistry. 2018; 57(31):4651-62.

133. Schnoes AM, Brown SD, Dodevski I, Babbitt PC. Annotation error in public databases: misannotation of molecular function in enzyme superfamilies. PLoS Comput Biol. 2009;5(12):e1000605.

134. Eddy SR. Accelerated profile HMM searches. PLoS Comput Biol. 2011;7(10): e1002195.

135. El-Gebali S, Mistry J, Bateman A, Eddy SR, Luciani A, Potter SC, et al. The Pfam protein families database in 2019. Nucleic Acids Res. 2019;47(D1): D427-D32.

136. Finn RD, Bateman A, Clements J, Coggill P, Eberhardt RY, Eddy SR, et al. Pfam: the protein families database. Nucleic Acids Res. 2014;42(Database issue):D222-30.

137. Altschu SF, Gish W, Miller W, Myers EW, Lipman DJ. Basic local alignment search tool. J Mol Biol. 1990;215:403-10.

138. Chen C, Huang H, Wu CH. Protein bioinformatics databases and resources. Methods Mol Biol. 2017:1558:3-39.

139. UniProt C. UniProt: the universal protein knowledgebase in 2021. Nucleic Acids Res. 2021;49(D1):D480-D9.

140. Slater GS, Birney E. Automated generation of heuristics for biological sequence comparison. BMC Bioinformatics. 2005;6:31.

141. Rice $P$, Longden I, Bleasby A. EMBOSS: the European molecular biology open software suite. TIG. 2000;16(6):276-7.

142. Benson DA, Cavanaugh M, Clark K, Karsch-Mizrachi I, Ostell J, Pruitt KD, et al. GenBank. Nucleic Acids Res. 2018;46(D1):D41-D7.

143. O'Neill LAJ. The Interleukin-1 receptor/toll-like receptor superfamily: signal transduction during inflammation and host defense. Sci Signal. 2000;44:re3.

144. Marchler-Bauer A, Anderson JB, Chitsaz F, Derbyshire MK, DeWeese-Scott C, Fong $\mathrm{JH}$, et al. CDD: specific functional annotation with the conserved domain database. Nucleic Acids Res. 2009;37(Database issue):D205-10.

145. Lu S, Wang J, Chitsaz F, Derbyshire MK, Geer RC, Gonzales NR, et al. CDD/ SPARCLE: the conserved domain database in 2020. Nucleic Acids Res. 2020; 48(D1):D265-D8

146. Letunic I, Bork P. 20 years of the SMART protein domain annotation resource. Nucleic Acids Res. 2018;46(D1):D493-D6.

147. Letunic I, Doerks T, Bork P. SMART 7: recent updates to the protein domain annotation resource. Nucleic Acids Res. 2012;40(Database issue):D302-5.
148. Krogh A, Larsson B, von Heijne G, Sonnhammer EL. Predicting transmembrane protein topology with a hidden Markov model: application to complete genomes. J Mol Biol. 2001;305(3):567-80.

149. Zallot R, Oberg NO, Gerlt JA. 'Democratized' genomic enzymology web tools for functional assignment. Curr Opin Chem Biol. 2018;47:77-85.

150. Shannon P, Markiel A, Ozier O, Baliga NS, Wang JT, Ramage D, et al. Cytoscape: a software environment for integrated models of biomolecular interaction networks. Genome Res. 2003;13(11):2498-504.

151. Li L, Stoeckert CJ Jr, Roos DS. OrthoMCL: identification of Ortholog groups for eukaryotic genomes. Genome Res. 2003;13:2178-89.

152. Mirarab S, Nguyen N, Guo S, Wang LS, Kim J, Warnow T. PASTA: Ultra-Large Multiple Sequence Alignment for Nucleotide and Amino-Acid Sequences. J Comput Biol. 2015;22(5):377-86.

153. Katoh $\mathrm{K}$, Toh $\mathrm{H}$. Recent developments in the MAFFT multiple sequence alignment program. Brief Bioinform. 2008;9(4):286-98.

154. Jones DT, Taylor WR, Thornton JM. The rapid generation of mutation data matrices from protein sequences. Bioinformatics. 1992;8(3):275-82.

155. Gouy M, Guindon S, Gascuel O. SeaView version 4: a multiplatform graphical user interface for sequence alignment and phylogenetic tree building. Mol Biol Evol. 2010;27(2):221-4.

156. Stamatakis A. RAxML version 8: a tool for phylogenetic analysis and postanalysis of large phylogenies. Bioinformatics. 2014;30(9):1312-3.

157. Miller MA, Pfeiffer W, Schwartz T. Creating the CIPRES Science Gateway for Inference of Large Phylogenetic Trees. In: Proceedings of the Gateway Computing Environments Workshop. New Orleans: GCE; 2010.

158. Giribet G, Edgecombe GD. The phylogeny and evolutionary history of arthropods. Curr Biol. 2019;29(12):R592-602.

\section{Publisher's Note}

Springer Nature remains neutral with regard to jurisdictional claims in published maps and institutional affiliations.
Ready to submit your research? Choose BMC and benefit from:

- fast, convenient online submission

- thorough peer review by experienced researchers in your field

- rapid publication on acceptance

- support for research data, including large and complex data types

- gold Open Access which fosters wider collaboration and increased citations

- maximum visibility for your research: over $100 \mathrm{M}$ website views per year

At $\mathrm{BMC}$, research is always in progress.

Learn more biomedcentral.com/submissions 